Illinois State University

ISU ReD: Research and eData

Theses and Dissertations

2-27-2016

\title{
A comparison of blood flow changes in tissues treated with therapeutic ultrasound and electrical stimulation
}

Ryanne McDaniel

Illinois State University, rmcdani@ilstu.edu

Follow this and additional works at: https://ir.library.illinoisstate.edu/etd

Part of the Kinesiology Commons

\section{Recommended Citation}

McDaniel, Ryanne, "A comparison of blood flow changes in tissues treated with therapeutic ultrasound and electrical stimulation" (2016). Theses and Dissertations. 527.

https://ir.library.illinoisstate.edu/etd/527

This Thesis is brought to you for free and open access by ISU ReD: Research and eData. It has been accepted for inclusion in Theses and Dissertations by an authorized administrator of ISU ReD: Research and eData. For more information, please contact ISUReD@ilstu.edu. 


\title{
A COMPARISON OF BLOOD FLOW CHANGES IN TISSUES TREATED WITH THERAPEUTIC ULTRASOUND AND ELECTRICAL STIMULATION
}

\author{
Ryanne L. McDaniel
}

\section{Pages}

Context: Therapeutic ultrasound and electrical stimulation both claim to achieve many effects on the body, one of which is increasing blood flow in tissues. Research on electrical stimulation in regards to blood flow has shown both increased and decreased blood flow, due to the electrode placement and the muscular contractions elicited during the treatment, while research on therapeutic ultrasound has provided mixed results, some suggesting that increased blood flow is seen only with intolerable treatment intensities for the patients. The two treatments have not been previously compared in the same study. Objective: To compare radial artery blood flow following therapeutic ultrasound and electrical stimulation. Design: Cross-over study. Setting: University laboratory. Participants: Thirty-six healthy volunteers ( 22 females, 14 males; $21.19 \pm 1.65$ years; $170.96 \pm 9.24 \mathrm{~cm} ; 70.69 \pm 11.54 \mathrm{~kg})$. Interventions: The participants were randomly assigned to therapeutic ultrasound or electrical stimulation for the first treatment session. The participants returned seven days later to receive the treatment they did not receive 
during the first treatment session. Therapeutic ultrasound was delivered at $1 \mathrm{MHz}$, continuous, $1.5 \mathrm{~W} / \mathrm{cm}^{2}, 10$ minutes. The muscle belly of the flexor-pronator mass of the non-dominant forearm was used as the treatment site. Electrical stimulation was delivered at $2-\mathrm{Hz}$ burst mode, 8 pulses/burst, pulse duration 180 microseconds, 15 minutes. The motor points of the flexor-pronator mass was used as the treatment site. This was determined by a visible contraction of the wrist flexors. Diagnostic ultrasound was used to measure radial artery blood flow volume. Main Outcome Measures: Radial artery blood flow volume was recorded before treatment, immediately post-treatment, 5 minutes post-treatment and 10 minutes post-treatment. Results: There were no significant differences found between blood flow measurements when comparing therapeutic ultrasound and electrical stimulation. There were also no significant differences in blood flow when comparing measurements within therapeutic ultrasound. However, there was a significant decrease in blood flow found with electrical stimulation when comparing baseline to immediately post-treatment $(\mathrm{P}=0.04)$ and 5 minutes post-treatment $(\mathrm{P}=$ $0.01)$, but not at 10 minutes post-treatment $(\mathrm{P}=0.16)$. Conclusions: Electrical stimulation temporarily reduces blood flow in the radial artery immediately following treatment and at 5 minutes following treatment. Electrical stimulation is useful in temporarily reducing blood flow and therefore may be beneficial in the control of edema or effusion.

KEYWORDS: Blood flow, Diagnostic ultrasound, Electrical stimulation, Radial artery, Therapeutic Ultrasound 


\title{
A COMPARISON OF BLOOD FLOW CHANGES IN TISSUES TREATED WITH THERAPEUTIC ULTRASOUND AND ELECTRICAL STIMULATION
}

RYANNE L. MCDANIEL

\begin{abstract}
A Thesis Submitted in Partial
Fulfillment of the Requirements for the Degree of

MASTER OF SCIENCE
\end{abstract}

School of Kinesiology and Recreation

ILLINOIS STATE UNIVERSITY

2016 
(C) 2016 Ryanne L. McDaniel 


\section{A COMPARISON OF BLOOD FLOW CHANGES IN TISSUES TREATED WITH THERAPEUTIC ULTRASOUND AND ELECTRICAL STIMULATION}

RYANNE L. MCDANIEL

COMMITTEE MEMBERS:

Todd McLoda, Chair

Noelle Selkow 


\section{ACKNOWLEDGMENTS}

The writer wishes to thank her thesis committee for providing guidance and always pointing her in the right direction throughout this process, her undergraduate athletic training preceptors and the athletes, for giving her the idea for this topic and her family, for their never ending support and love throughout my education and beginning stages of her career as an athletic trainer.

R. L. M. 


\section{CONTENTS}

ACKNOWLEDGMENTS $\quad$ i

$\begin{array}{ll}\text { CONTENTS } & \text { ii }\end{array}$

TABLES

FIGURES

CHAPTER

I. INTRODUCTION 1

II. REVIEW OF RELATED LITERATURE 4

Forearm Anatomy $\quad 4$

Skin 4

Muscle $\quad 5$

Vascular Supply $\quad 7$

Nerve Supply $\quad 10$

$\begin{array}{ll}\text { Electrical Stimulation } & 10\end{array}$

Theories of Use $\quad 10$

Benefits of Electrical Stimulation $\quad 12$

Muscular Contraction by Electrical Stimulation $\quad 14$

Blood Flow and Electrical Stimulation $\quad 18$

Contraindications of Electrical Stimulation $\quad 20$

$\begin{array}{ll}\text { Therapeutic Ultrasound } & 21\end{array}$

Theories of Use $\quad 21$

Benefits of Therapeutic Ultrasound 23

Contraindications of Therapeutic Ultrasound 30

$\begin{array}{ll}\text { The Healing Process } & 31\end{array}$ 
Inflammatory Response Phase

III. METHODS

Design 35

Participants

35

Instrumentation

36

Procedures

37

Statistical Analysis

IV. RESULTS

V. DISCUSSION 


\section{TABLES}

Table

Page

1. Flow Volume for Therapeutic Ultrasound and Electrical Stimulation

2. Time Average Mean Velocity for Therapeutic Ultrasound and Electrical Stimulation

3. Flow Volume and Time Average Mean Velocity for Therapeutic Ultrasound

4. Flow Volume and Time Average Mean Velocity for Electrical Stimulation 


\section{FIGURES}

Figure

Page

1. Diagnostic ultrasound 38

2. Therapeutic ultrasound 39

3. Electrical stimulation $\quad 40$ 


\section{CHAPTER I}

\section{INTRODUCTION}

Therapeutic ultrasound and electrical stimulation are popular modalities used for injury healing and recovery in the athletic training and physical therapy settings. Therapeutic ultrasound is used to increase blood flow, increase elasticity of tissues, reduce muscle spasm and provide analgesic effects. ${ }^{1}$ Electrical stimulation is mainly used to reduce pain, control edema, reeducate muscles, relax muscle spasm and increase blood flow to the treatment area. ${ }^{2}$ Both modalities claim to improve blood flow to the area, but it has not been proven whether one modality is more effective in providing this effect.

The effect of increased blood flow from therapeutic ultrasound is heavily dependent on the wave frequency, intensity of beam over the transducer area, duration of treatment, movement speed of the sound head, coupling agent used, type of tissues treated and size of treatment area. ${ }^{3}$ If the goal of therapeutic ultrasound is to increase blood flow to the treatment area, it is essential that the clinician understand the exact parameters that are necessary to increase blood flow. Research on therapeutic ultrasound and its heating effects are conflicting and some studies ${ }^{4,5}$ suggest that significant changes in blood flow are seen with intensities intolerable for patients. 
Physiological changes due to electrical stimulation have been studied, but few studies on muscular or skin blood flow have been conducted. ${ }^{6-8}$ One study found that using motor-level 2-Hz transcutaneous electrical nerve stimulation (TENS) showed significant blood flow increases in the trapezius muscle, when compared to both sensorylevel $80-\mathrm{Hz}$ and subsensory TENS. ${ }^{6}$ This study also found minimal blood flow increases in the skin post-stimulation with motor-level $2-\mathrm{Hz}$ and subsensory TENS. ${ }^{6}$ Another study ${ }^{9}$ found that neuromuscular electrical stimulation (NMES) may be beneficial in preventing deep vein thrombosis (DVT) following orthopedic surgery by increasing peak venous velocity and blood flow in the operated limb. Increased venous velocity and blood flow prevents blood from becoming stagnant, which reduces the risk of developing DVT. In regards to the potential to decrease blood flow Levine et al. ${ }^{10}$ found that applying electrical stimulation to the gluteus maximus of healthy individuals decreased blood flow during the stimulation rest periods of the treatment. The authors suggest that with the tissue distortion, peak occlusion isn’t achieved for a relatively long time, therefore leading to the decrease in blood flow. ${ }^{10}$

While both therapeutic ultrasound and electrical stimulation are useful tools in the clinical setting, it is difficult to know whether or not the treatment goal is being achieved, i.e. increased blood flow. This is due to the placebo effect, in that athletes believe these treatments are accomplishing the desired outcomes, even though that may not be the case. ${ }^{7,11}$ Preparing athletes for activity in the athletic training setting is of vital importance in order to decrease the risk of injury. It would be useful to the clinician and beneficial to the patient to know more about the blood flow changes that occur as a result of either 
therapeutic ultrasound or electrical stimulation. If the goal is to increase blood flow and sustain the increase to optimize recovery from an injury, the clinician needs to understand the choices available among commonly applied modalities. Both therapeutic ultrasound and electrical stimulation can be used to increase blood flow, but it is not fully understood which modality produces more hyperemia or which one sustains the hyperemia longer. Determining which modality is more effective at increasing and sustaining blood flow will help clinicians make better decisions for treatment, therefore giving the patients the best care possible.

The purpose of this study was to directly compare electrical stimulation to therapeutic ultrasound in regard to changes in blood flow. The authors hypothesize that electrical stimulation will be more effective at increasing and sustaining blood flow than therapeutic ultrasound. 


\section{CHAPTER II}

\section{REVIEW OF RELATED LITERATURE}

\section{Forearm Anatomy}

Skin

Skin is one of the more versatile organs of the body and is vital in maintaining homeostasis, by preventing many harmful substances and microorganisms from entering the body, regulating body temperature, housing sensory receptors and synthesizing various chemicals. ${ }^{12}$ It also contains immune system cells and excretes small quantities of waste. $^{12}$ There are three layers that comprise the skin: epidermis, dermis and subcutaneous layer. ${ }^{13}$

The epidermis is the most superficial layer of the skin. It is composed of stratified squamous epithelium and lacks blood vessels. ${ }^{12}$ The main function of the epidermis is to shield the moist underlying tissues against excess water loss, mechanical injury and the effects of harmful chemicals. ${ }^{12}$ It also keeps out pathogens that can damage the underlying tissues. $^{12}$

The dermis is the second layer of the skin. It binds the epidermis to the underlying tissues and the subcutaneous layer. ${ }^{13}$ It is composed of dense irregular connective tissue 
including collagenous and elastic fibers in a gel-like ground substance, and contains muscle fibers. ${ }^{14}$ Smooth muscle fibers are connected to hair follicles and glands, while skeletal muscle fibers are connected to the dermis, especially in the skin of the face. ${ }^{12}$ There are many nerve cell processes scattered throughout the dermis, such that motor processes carry impulses to dermal muscles and glands, while sensory processes carry impulses away from the specialized sensory receptors, such as Pacinican corpuscles, Meissner's corpuscles and free nerve endings. ${ }^{12}$ The main components of the dermis are blood vessels, hair follicles, sebaceous glands and sweat glands. ${ }^{14}$

The subcutaneous layer is the deepest layer of the skin. It is composed of the collagenous and elastic fibers that are continuous with the dermis. ${ }^{12}$ The purpose of the subcutaneous layer is to insulate by conserving body heat and preventing heat from entering the body thereby maintaining thermal homeostasis. ${ }^{13}$ The subcutaneous layer also contains major blood vessels that supply the skin as well as branching, smaller vessels that supply blood to the dermis. ${ }^{12}$ This layer is vital to the heat production and heat loss function of the skin.

Heat is a product of cellular metabolism, such that when body temperature rises above a set point, nerve impulses stimulate structures in the skin and other organs to release heat. ${ }^{12}$ This process includes the skeletal and smooth muscle cells of the skin. ${ }^{12}$ The heat production and loss helps in the maintenance of homeostasis of the body.

Muscle

Muscle is comprised of many components and is responsible for movement of the body. Individual skeletal muscles are separated and held in position by layers of dense 
connective tissue called fascia. ${ }^{12}$ Fascia surrounds each muscle and projects beyond the end of its muscle fiber forming a tendon. ${ }^{12}$ The fibers in the tendon intertwine with the periosteum of the bone, attaching muscle to bone. ${ }^{12}$ There are three primary layers that comprise muscle: epimysium, perimysium and endomysium. ${ }^{12}$

The epimysium is the layer of connective tissue that closely surrounds skeletal muscle. ${ }^{12}$ Perimysium extends inward from the epimysium and separates the muscle tissue into small sections called fascicles, and each muscle fiber within a fascicle lies within a layer of connective tissue, which is the endomysium. ${ }^{12}$ While the three layers of muscle are responsible for function, there are specific tissues responsible for contraction. The myosin, actin, troponin and tropomyosin form the contractile unit of the muscle. ${ }^{12}$ The contractile unit is supplied by blood vessels and nerve in support of the contractile function and, depending upon the origin and insertion of the muscle, provide for the specific action of the skeletal muscle. Many blood vessels and nerves pass through these layers, which assist with the function of the muscles.

The rotators of the forearm are the supinator and pronator teres. The supinator originates on the lateral epicondyle of the humerus and the crest of the ulna and inserts on the lateral surface of the radius, and its main action is to assist the biceps brachii in supination of the forearm. ${ }^{12}$ The pronator teres originates on the medial epicondyle of the humerus and coronoid process of the ulna and inserts on the lateral surface of the radius, and its main action is pronation of the forearm. ${ }^{12}$ The rotators and wrist flexors are on the anterior forearm. 
The wrist flexors of the forearm are the flexor carpi radialis, flexor carpi ulnaris, palmaris longus, flexor digitorum profundus and flexor digitorum superficialis. The flexor carpi radialis originates at the medial epicondyle of the humerus and inserts at the base of the second and third metacarpals. Its main actions are wrist flexion and radial deviation. ${ }^{12}$ The flexor carpi ulnaris originates at the medial epicondyle of the humerus and olecranon process and inserts on the carpal and metacarpals and its main actions are wrist flexion and ulnar deviation. ${ }^{12}$ The palmaris longus originates on the medial epicondyle of the humerus and inserts on the fascia of the palm. Its only action is wrist flexion. ${ }^{12}$ The flexor digitorum profundus originates on the anterior surface of the ulna and inserts at the base of the distal phalanges in fingers 2-5 and its only action is flexion of the distal interphalangeal joints. ${ }^{12}$ The flexor digitorum superficialis has three heads that originate on the medial epicondyle of the humerus, coronoid process and the radius. ${ }^{12}$ It inserts on the tendons of the fingers and its action is finger flexion. ${ }^{12}$

The anterior compartment of the forearm is known as the flexor-pronator mass. ${ }^{15}$ There are three layers of the flexor-pronator mass: superficial, intermediate and deep. ${ }^{15}$ The superficial layer consists of the pronator teres, flexor carpi radials, palmaris longus and flexor carpi ulnaris. ${ }^{15}$ The intermediate layer, which is directly beneath the superficial layer, consists of the flexor digitorum superficialis. ${ }^{15}$ The deep layer consists of the flexor digitorum profundus, flexor pollicis longus and pronator quadratus. ${ }^{15}$

\section{Vascular Supply}

There are many components that comprise the vascular supply of the forearm. Blood is a complex mixture of cells, cell fragments and dissolved biochemicals to 
transport nutrients, oxygen, wastes and hormones. ${ }^{12}$ The purpose of blood is to maintain the stability of the interstitial fluid as well as management of heat. ${ }^{12}$ The blood vessels form a closed circuit of tubes that carry blood away from the heart and back again, including arteries, arterioles, capillaries, venules and veins. ${ }^{12}$

Arteries are strong elastic vessels adapted for carrying the blood away from the heart under high pressure. ${ }^{13}$ Arterioles are subdivided arteries that are thinner and finer branches. ${ }^{12}$ The walls of the arteries and arterioles are innervated by the sympathetic branches of the autonomic nervous system. ${ }^{12}$ Vasoconstriction is caused by the vasomotor fiber stimulation of the smooth muscle cells, which causes constriction of the arteries or arterioles. ${ }^{12}$ Vasodilation is caused by inhibition of the vasomotor impulses, leading to smooth muscle relaxation and increase in diameter of the vessel. ${ }^{12}$ Capillaries are the smallest blood vessels in the body and connect the smallest arterioles and the smallest venules. ${ }^{12}$ Veins carry blood back to the atria and follow pathways that parallel those of the arteries. ${ }^{13}$ In the upper and lower limbs, the veins contain valves to aid in returning blood to the heart but close to prevent reversal of flow. ${ }^{12}$ Venules are microscopic vessels that continue from the capillaries. ${ }^{12}$ The vascular supply in the forearm is vital to proper function of the upper extremity.

The brachial artery is the main supply of blood to the upper extremity. It courses along the humerus to the elbow and gives rise to the deep brachial artery that curves posteriorly around the humerus and supplies the triceps muscle. ${ }^{12}$ Shorter branches of the brachial artery pass into the muscles on the anterior side of the arm, while other branches descend on each side of the elbow and connect with the arteries of the forearm. ${ }^{12}$ The 
arterial network allows blood to reach the forearm even if a portion of the distal brachial artery becomes obstructed. ${ }^{12}$ The brachial artery divides into the ulnar and radial arteries.

The ulnar artery leads downward on the ulnar side of the forearm to the wrist and some of its branches join the anastomosis around the elbow joint, while others supply blood to flexor and extensor muscles in the forearm. ${ }^{12}$ The anterior and posterior ulnar recurrent arteries anastomose with the inferior and superior ulnar collateral arteries. ${ }^{15}$ The common interosseous artery arises from the distal part of the cubital fossa and divides into the anterior and posterior interosseous artery. ${ }^{15}$ The anterior interosseous artery passes distally on the anterior aspect of the interosseous membrane, while the posterior interosseous artery runs between the superficial and deep layers of the extensor muscles. ${ }^{15}$ The radial artery is vital to proper function of the forearm.

The radial artery extends along the radial side of the forearm to the wrist and the closer it gets to the wrist, it becomes more superficial, therefore being a convenient vessel for taking a pulse. ${ }^{12}$ The pulse can be felt on the forearm easily because it lies on the anterior surface of the radius and is covered only in skin and fascia. ${ }^{15}$ The branches of the radial artery join the anastomosis of the elbow and supply the lateral muscles of the forearm. ${ }^{12}$ The radial recurrent artery joins with the radial collateral artery, a branch of the deep artery in the forearm. ${ }^{15}$ The palmar and dorsal carpal branches of the radial artery joins with the corresponding branches of the ulnar artery as well as the terminal branches of the anterior and posterior interosseous arteries. ${ }^{15}$ 
Nerve Supply

The forearm receives nerve supply from the median, ulnar and radial nerves. The median nerve is the principal nerve of the anterior compartment of the forearm. ${ }^{15}$ It is responsible for supplying the superficial and intermediate layers of the forearm except for the flexor carpi ulnaris and the deep layer of the forearm except for the ulnar half of the flexor digitorum profundus. ${ }^{15}$ The ulnar nerve supplies the flexor carpi ulnaris and the ulnar part of the flexor digitorum profundus and passes through the Tunnel of Guyon. ${ }^{15}$ The radial nerve is primarily responsible for motor and sensory functions in both the posterior arm and forearm. ${ }^{15}$

\section{Electrical Stimulation}

\section{Theories of Use}

Electrical stimulation is used for many different reasons in the clinical setting. While literature supporting the theories of use is limited, research has been done to determine the efficacy of the electrical stimulation treatment. ${ }^{6-9,16-38}$ In clinical settings, electrical stimulation is commonly used to increase muscle strength, increase range of motion, reduce edema, reduce atrophy, heal tissue and decrease pain. ${ }^{39,40}$ Along with a variety of theories, there are many different types of electrical stimulation.

One of the more frequently used electrical stimulation settings is transcutaneous electrical nerve stimulation (TENS). TENS is an alternate form of electrical stimulation that has been used at high frequencies for pain relief ${ }^{21}$, but more recently has been used at low frequencies to target specific sensory nerve fibers while not activating motor 
fibers. ${ }^{24}$ Skin blood flow increases have been seen in healthy individuals at low frequency TENS (2 Hz), but not with high frequency TENS $(100 \mathrm{~Hz}){ }^{6}$ However, in another study, skin blood flow in ischemic tissue was found to increase with high frequency TENS (80 $\mathrm{Hz}$ ), which elicits a strong, tingling sensation. ${ }^{6}$ Fifteen minutes of low frequency TENS (4 Hz) has been shown to significantly increase local skin blood flow, in comparison with high frequency TENS $(110 \mathrm{~Hz})$ when the electrodes are placed over the median nerve. ${ }^{6}$ The authors of this study suggest that the "muscle pump" accumulation of local metabolic vasodilator substances and flow-induced vasodilation produce relaxing factors when TENS electrodes are placed over the muscle belly, increasing blood flow to the muscle. ${ }^{6}$ Low frequency TENS $(4 \mathrm{~Hz})$ has been found to increase local blood flow at the forearm and the second and third fingertips only when the intensity was above the motor threshold, but no significant changes were found in local or distal skin temperature. ${ }^{7}$ TENS is also commonly used for pain relief. ${ }^{17,22,38}$ Overall, the theory that TENS relieves pain is due to an analgesic effect produced as a result of counter stimulation of the nervous system modifying the perception of pain. ${ }^{38}$

Another type of electrical stimulation is neuromuscular electrical stimulation (NMES). The most common application for NMES is preventing muscle atrophy and increasing blood flow. NMES has been used frequently in paralyzed and bed-ridden patients to promote physiological and functional improvements in paralyzed limbs, as well as counteract musculoskeletal atrophy ${ }^{32}$ by altering the intrinsic characteristics of the individual's paralyzed tissue. ${ }^{18}$ In regards to improving blood flow, NMES is most commonly applied to bed-ridden individuals to prevent a deep vein thrombosis (DVT). The theory of using NMES for this purpose, is that it creates an artificial calf muscle 
pump ${ }^{9}$ during the active cycle of the treatment. ${ }^{19}$ The electrodes are placed over the motor points of the calf musculature, resulting in ejection of blood from the venous compartment of the lower leg; the venous flow is similar to that of a voluntary muscle contraction, with relaxation of the muscle to allow the vessels to refill and the one-way valves preventing backflow. ${ }^{19}$

Patterned electrical nerve stimulation (PENS) is another form of electrical stimulation, most commonly used in post-surgical individuals, as well as during activity. The most common surgical treatments in which PENS is used are total knee and total hip arthroplasty. ${ }^{27}$ PENS is found to replicate typical firing patterns of muscles (reciprocal muscle pairs) in triphasic patterns (ballistic), biphasic patterns (reciprocal) or functional patterns.$^{27}$ Clinical evidence has shown that functional patterns of electrical stimulation, which are task specific and in conjunction with voluntary movement, improves motor learning and functional performance. ${ }^{27}$ This is ideal for post-surgical patients because this leads to faster recovery and similar functionality as compared to before they were injured. $^{27}$

\section{Benefits of Electrical Stimulation}

While there has been little research on electrical stimulation, evidence has shown many benefits of its use. Patients have seen improvements in functional performance $^{27,30,32,38}$, muscle reeducation following ACL reconstruction ${ }^{28}$, increased blood flow ${ }^{6-9,16,18,19,22-24,26,29,31,33,34,36,41,42}$, reduced neuromuscular activation deficits $^{16,17,20,21,24,26,28,30,32,37,38,42}$, pain reduction and improved psychological wellbeing. 
Some electrical stimulation units are portable and user-friendly, so patients can use them while performing rehabilitation exercises and at home following surgery.

While TENS has many benefits associated with its use, the main benefit found in the research is pain reduction. Long-term follow up reports of patients using TENS has shown a $40-58 \%$ decrease in pain, as well as a reduction in interference with work and social activities ${ }^{22}$; increased activity levels and decreased use of other therapies and medications have also been associated with the use of TENS. ${ }^{22}$ The neurophysiological basis for pain relief from TENS is directly based on the 'gate control' principle of pain $^{2,22}$, such that positive analgesic effects have been found in patients with chronic musculoskeletal pain, knee osteoarthritis and rheumatoid arthritis. ${ }^{22}$ Most recent research has found additional benefits to other forms of electrical stimulation.

Multiple benefits of NMES treatment have been investigated and determined. In addition to rehabilitation post total knee arthroplasty, NMES can reduce neuromuscular activation deficits and postoperative hospital stay while improving walking speed and extensor lag, as well as improving mental health status. ${ }^{38}$ In a recent study, an increase in electromyographic activity in the biceps femoris after electrical stimulation of the patellar tendon graft, indicates that the ACL-hamstring reflex in the human knee after ACL reconstruction is re-established. ${ }^{28}$ In regards to improving blood flow to the treatment area, this appears to be the most investigated benefit of NMES. In situations of low levels of patient mobility, NMES artificially activates the calf muscle pump, preventing stagnation of blood and development of DVT. ${ }^{9}$ Also, in regards to improving hemodynamics, NMES is an alternative that competes favorably with existing methods, 
especially in ease of use and patient compliance. ${ }^{19}$ The NMES device is portable, noiseless and does not require a clinician to operate, therefore making it easy to use at home; removal of the electrodes is not necessary for patient movement, as stimulation can be paused. ${ }^{19}$ The device can be worn while the individual is immobile, standing or walking, so it is ideal to use during the early immobilization stage following surgery and throughout the rehabilitation period at home. ${ }^{19}$ The physiological muscle contraction during walking can be reproduced with the use of NMES, which results in a large increase in venous return. ${ }^{19}$

Other various benefits of electrical stimulation have been found in clinical research. PENS may have the potential to improve functional performance in healthy, nonathletic and athletic populations by altering neuromuscular recruitment, by enhancing the timing of recruitment. ${ }^{27} \mathrm{~A}$ study concerning wound healing found that stimulating gluteal muscles in able-bodied subjects showed a redistribution of interface pressures away from the ischial region along with an increase in local blood flow while the muscle was being actively stimulated. ${ }^{18}$ Additionally, muscular vascularization has been found to increase as early as four days after starting low-frequency electrical stimulation ${ }^{18}$; capillary density can triple in paralyzed muscles after two weeks of moderately intensive stimulation, which improves fatigue resistance. ${ }^{18}$

\section{Muscular Contraction by Electrical Stimulation}

One common therapeutic use of electrical stimulation is to produce muscle contractions. There are several indicated uses for motor level electrical stimulation. The resulting muscle contraction can help the clinician with meeting treatment goals that may 
include reducing pain, countering disuse atrophy, increasing blood flow, overcoming reflex inhibition, reducing spasm, and overcoming neurologic deficits. ${ }^{2}$ These treatment goals may be related to treating conditions that include spinal accessory nerve injury ${ }^{16}$, spinal cord injury ${ }^{21}$, sprains, strains and joint dysfunction. Among the specific indicated uses of motor level electrical stimulation are pressure ulcers ${ }^{18,33,36,38}$, reeducation of muscles following surgery ${ }^{28}$ and treatment of nerve dysfunction. ${ }^{2,17,22,27}$

Muscle activation by electrical stimulation for prevention of pressure ulcers (PUs) has been found to improve interface pressure distribution and intrinsic risk factors for the development of these sores. ${ }^{33}$ Electrical stimulation of the gluteal muscles temporarily decreases interface pressure below the ischial tuberosities, which causes a change in muscle shape and tone and mitigates the pressure from beneath the ischial tuberosities. ${ }^{33}$ In a recent study, the authors compared the stimulation-rest interval of 1:1 s during three minutes of electrical stimulation to a different protocol of $1: 4 \mathrm{~s}$ of electrical stimulation. ${ }^{33}$ With this interval, the activated muscles would be allowed more time to recover from contractions, which improved the force of the contractions and decreased fatigue. ${ }^{33}$ At the end of this study, the authors found that ischial tuberosity pressure and pressure gradient during electrical stimulation compared with rest were not significantly different between the protocols, although there was a tendency for larger reductions with protocol 1:4 s than with protocol 1:1 s. ${ }^{33}$ In another study investigating electrical stimulation to treat pressure sores, the authors utilized pigs as the subjects and they found similar results. ${ }^{34}$ The results show that the use of intermittent electrical stimulation significantly reduced the extent of deep tissue injury in the pigs. ${ }^{34}$ By the fourth week of the study, the authors found that the volumetric extent of injury in the loaded legs of the pigs that did not receive electrical 
stimulation was nearly seven times larger than in the pigs that received electrical stimulation. ${ }^{34}$ This shows that electrical stimulation can counteract both mechanical and vascular factors that lead to deep tissue injury development. ${ }^{34}$

NMES interventions for skeletal muscle atrophy and spasticity are typically used at electrical currents of 30 to $70 \mathrm{~Hz}$ range to elicit tetanic contractions in target muscles in order to produce movement. ${ }^{21}$ In another study regarding muscular contraction and electrical stimulation, NMES was placed over the spinal accessory nerve rather than the muscle belly in order to augment the central contribution to electrically stimulated contractions, which may help reduce muscle atrophy. ${ }^{16}$ During this study, bilateral exercise and NMES were combined to address central and peripheral mechanisms that contribute to trapezius dysfunction. ${ }^{16}$ This was the first study that investigated an intervention involving a combination of wide pulse-width, high-frequency NMES with bilateral exercise for trapezius dysfunction following the return of conduction along the spinal accessory nerve. ${ }^{16}$ This novel application of NMES was used to help reduce muscle atrophy and enhance the electrically-evoked sensory volley sent to the central nervous system (CNS) to increase the activity and excitability in sensorimotor pathways. ${ }^{16}$ Another application of NMES that is similar to the previously discussed method is called electrical stimulation resistance training (ES-RT) ${ }^{21}$ This method is a combination of electrical stimulation and application of external load of dead weight resistance, which has been shown to increase muscle size in a patient with spinal cord injury. ${ }^{21}$ 
In a study conducted by Giavedoni et al. ${ }^{26}$, the authors investigated the application of a short NMES program in preventing skeletal muscle function deterioration in patients with chronic obstructive pulmonary disease (COPD) during severe exacerbations of COPD (SECOPD). The authors found that the effect of NMES on muscle strength in the stimulated leg was directly related to the amount of energy applied throughout the 14 days treatment. ${ }^{26}$ The results also demonstrated that there was a clear difference in the amount of energy tolerated by the male patients in comparison with the females. ${ }^{26}$ The male subjects were able to sustain higher intensities throughout the treatment and reach higher stimulation levels by the end of program in comparison to the female subjects. ${ }^{26} \mathrm{In}$ addition to these findings, the study also demonstrated that the NMES program not only prevented deterioration of muscle function, but also improved muscle strength in the stimulated legs in comparison with the control legs. ${ }^{26}$

TENS has also been applied to patients suffering from temporomandibular disorder (TMD). This technique has shown to produce an antalgic effect in symptomatic patients along with a positive relaxing effect on the masticatory muscles. ${ }^{42}$ Following the application of TENS during this study, a reduction in muscle activity was observed in all the muscles in the motor and sensorial threshold of stimulation groups. ${ }^{42}$ In the control group, only the right masseter muscle, left digastric anterior and right digastric anterior showed a reduction in muscle activity values, but their findings were not statistically significant. ${ }^{42}$ However, significant pre- and post-treatment differences were observed in the motor and sensory threshold of stimulation groups for the left and right temporalis anterior and left and right masseter muscles. ${ }^{42}$ 


\section{Blood Flow and Electrical Stimulation}

Electrical stimulation is commonly used to improve blood flow in muscles, which assists in the healing process of injury, by bringing healing nutrients to the damaged tissue. $^{43}$ The research is limited and varied as to whether electrical stimulation is effective in improving blood flow. Some of the studies have included patients recovering from total hip arthroplasty and bed-ridden patients, in order to prevent DVT from developing. ${ }^{9,19}$ Another study has applied electrical stimulation to upper trapezius trigger points. ${ }^{6}$ These studies had the same goal to determine whether electrical stimulation improved blood flow, and the results showed that blood flow did increase with electrical stimulation.

NMES can be used as a DVT prevention method when applied to the calf muscle. The calf muscle activation compresses the intramuscular and surrounding veins, which raises venous blood pressure and forces blood back toward the heart. ${ }^{9}$ Contracting the calf muscles increases lower limb blood flow in order to meet the metabolic demands of

exercising skeletal muscles. ${ }^{9}$ The increase in lower limb blood flow prevents the pooling and stagnation of blood in the lower limb. ${ }^{9}$ NMES has been used on patients with limited mobility, especially following total hip arthroplasty. ${ }^{9}$ Broderick et al. ${ }^{9}$ found that the percentage increase in peak velocity produced by NMES in the non-operated limb $(13.8 \pm$ 7.6 versus $43.9 \pm 13.7 \mathrm{~cm} / \mathrm{s})$ was significantly higher than that of the operated limb $(12 \pm$ 5.9 versus $22.5 \pm 16.8 \mathrm{~cm} / \mathrm{s}$ ) in total hip arthroplasty patients. NMES elicited calf muscle contractions resulted in mean velocities that were $178 \%$ higher than resting in the operated $\operatorname{limb}(2.3 \pm 1.4$ versus $7 \pm 5.7 \mathrm{~cm} / \mathrm{s})$ and $354 \%$ higher than resting in the non- 
operated $\operatorname{limb}(3.7 \pm 2$ versus $12.9 \pm 4.3 \mathrm{~cm} / \mathrm{s}) .{ }^{9}$ In another study conducted by Broderick et al. ${ }^{19}$, in which the authors compared intermittent pneumatic compression (IPC) to NMES in regards to blood flow in the calf, the results showed that NMES produced 1.7 times the ejected volume in comparison to calf IPC (15.4-30.81 ml). The authors determined that this occurred because NMES produces a physiological muscle contraction similar to that observed during normal walking, resulting in the large increase in ejected volume, therefore, decreasing the risk of developing DVT. ${ }^{19}$ Both studies used diagnostic ultrasound to measure blood flow.

There have been some studies comparing electrically stimulated muscular contractions and voluntary muscle contractions in regards to blood flow. Miller et al. ${ }^{29}$ found that following a TENS treatment, participants had an increase in blood flow $(4.5 \pm$ 0.1 versus $6.9 \pm 0.2 \mathrm{ml} / 100 \mathrm{ml} / \mathrm{min})$ and a decrease in vascular resistance $(22.8 \pm 0.8$ versus $14.0 \pm 0.5)$ that persisted until the 15 second post exercise measurements, but overall, there was no time $\mathrm{x}$ condition interaction for either blood flow or vascular resistance. These results were obtained through electromyographic images. The authors suggest that the results may be secondary to a basic qualitative difference in electrically evoked versus voluntary muscle contractions. ${ }^{29}$ In electrically stimulated contractions, there is a partial reversal in the order in which motor units are recruited (large-to-small, as opposed to small-to-large) and motor units fire synchronously with electrically induced contractions as opposed to asynchronously with voluntary contractions. ${ }^{29}$ The reversal of the recruitment order during TENS would be expected to alter proportions of type I (slow-twitch) versus type II (fast-twitch) muscle fibers participating in the contraction. $^{29}$ The authors suggest that recruitment of more type II fibers during TENS 
could lead to an increase in the release of vasodilatory metabolites such as hydrogen ions, adenosine and phosphate. ${ }^{29}$

In regards to specific TENS parameters and the effects on blood flow, Sandberg et al. ${ }^{6}$ conducted a study on upper trapezius trigger points, using photoplethysmography to measure blood flow. The results of this study showed that blood flow rose rapidly with the onset of motor-level 2-Hz TENS and after the treatment, blood flow quickly returned to baseline levels. ${ }^{6}$ There was a modest blood flow increase $(25 \%$ relative change) shown with subsensory TENS that the authors determined was not related to the onset of stimulation, but rather showed a slowly increasing pattern throughout the study. ${ }^{6}$ There was a significant difference seen among the TENS interventions in that the mean muscle blood flow increase was significantly larger with motor-level 2-Hz TENS compared with both sensory-level $80-\mathrm{Hz}$ TENS and subsensory TENS. ${ }^{6}$ No difference was found between sensory-level $80-\mathrm{Hz}$ TENS and subsensory TENS. ${ }^{6}$ During the 15 -minute poststimulation period, no significant difference in mean blood flow increase was found between motor-level 2-Hz TENS and subsensory TENS, both of which were superior to sensory-level 80-Hz TENS. ${ }^{6}$ The authors also looked at skin blood flow during this study and found that when comparing stimulated and non-stimulated shoulders, there were no increases seen following any of the TENS treatments. ${ }^{6}$

\section{Contraindications of Electrical Stimulation}

As with all treatments, there are some contraindications associated with the application of therapeutic electrical stimulation. Depending on the settings for electrical stimulation, rapid onset of muscle fatigue during repeated contractions can result in 
muscle force decay and slowing of muscle contractile properties. ${ }^{32}$ Patients may also be anxious about using electrical stimulation, especially for the first treatment. In one study the group receiving electrical stimulation experienced a significantly higher heart rate than the control group, which is potentially due to their level of anxiety concerning the treatment. ${ }^{8}$ Discomfort and pain are important contraindications for the application of electrical stimulation. In one study involving therapeutic electrical stimulation, individuals were asked to report whether the intensity decreased during the treatment in a study; if this was the case, the intensity was increased again in order to maintain the initial sensation. ${ }^{6}$ Researchers believe this procedure may have encouraged the subjects to accept an intensity that was more intense than intended because some of the participants reported discomfort or pain after the stimulation. ${ }^{6}$ Along with discomfort and pain, skin irritation and chemical burns have been found with electrical stimulation, especially in individuals with hypersensitive skin. ${ }^{25}$ This type of skin irritation typically occurs with the use of monophasic stimulation because of the unidirectional flow in the circuit leads to an alkaline buildup at the positive electrode and an acidic buildup at the negative electrode. $^{25}$

There are many contraindications associated with specific types of electrical stimulation as well. In regards to TENS the main contraindications are in individuals with a pacemaker, heart disease, and application at the transthoracic area, due to the potential of creating an irregular electrical rhythm in the heart. ${ }^{2}$ Also, TENS should be discontinued if skin irritation develops. ${ }^{2}$ With the application of NMES, the main contraindications for this electrical stimulation are in individuals with a pacemaker, over the heart or the brain, over recent or nonunion fractures and over potential malignancies. ${ }^{2}$ 


\section{Therapeutic Ultrasound}

\section{Theories of Use}

Therapeutic ultrasound has many theories of use and they are generally labeled together as nonthermal and thermal effects. Thermal effects of therapeutic ultrasound include increased blood flow ${ }^{44,45}$, reduction in muscle $\operatorname{spasm}^{46,47}$, increased extensibility of collagen fibers ${ }^{48,49}$ and a proinflammatory response. ${ }^{50,51}$ Nonthermal effects of therapeutic ultrasound are increased cellular diffusion, increased membrane permeability, and improved tissue regeneration due to increased protein synthesis. ${ }^{3,52}$

Ultrasound has been used to treat a variety of disorders and it is most commonly used in the management of skin wounds and soft tissue injuries. ${ }^{53}$ In regards to thermal effects of ultrasound, the main purpose of a thermal setting is to improve blood flow and provide analgesic effects to the tissue in chronic soft tissue injuries that result in inflammation. ${ }^{3}$ When properly applied, therapeutic ultrasound provides thermal effects that increase tissue temperature, increase blood flow and extensibility of tissues, relax muscle spasm and provide analgesia to local tissues. ${ }^{1}$ A reduction in pain and tenderness and increased muscle strength in delayed-onset muscle soreness (DOMS) were found in one study.$^{53}$ Other effects of thermal ultrasound include changes in nerve conduction velocity, increased enzymatic activity, changes in contractile activity of skeletal muscle, increased collagen extensibility, increased local blood flow and increased pain threshold. ${ }^{3}$ Thermal effects can be achieved with continuous ultrasound and adequate intensity of the treatment. $^{54}$ 
Nonthermal effects of therapeutic ultrasound are more commonly desired in the early stages after injury. ${ }^{53}$ Reports have found that nonthermal effects aid the immune response by inducing vasodilation of arterioles and activation of adhesion molecules, which are regulated by signal-transduction pathways. ${ }^{53}$ This indicates that ultrasound modifies cellular activity by modulating one or more signal-transduction pathways. ${ }^{53}$ One research study found that ultrasound affects the immune response, such that it can modulate vasoconstriction; lymphocyte adhesion properties of endothelium; mast cell degranulation; enhance phagocytosis; increase production of growth factors by macrophages; improve calcium fluxes in fibroblasts; increase angiogenesis; increase proliferation of T-cells, osteoblasts, fibroblasts and many proteins associated with inflammation and repair; and accelerates thrombolysis. ${ }^{55}$ Nonthermal effects are desired when heating of the injured tissues should be minimized and can be accomplished with either continuous or pulsed ultrasound depending upon the intensity of the ultrasound. ${ }^{53}$

\section{Benefits of Therapeutic Ultrasound}

Therapeutic ultrasound has been found to provide many benefits to patients recovering from soft tissue injuries. This treatment is most commonly used for soft tissue injuries, but some recent studies have found benefits of ultrasound in the treatment of fractures. ${ }^{56-60}$ Most of the previously investigated benefits are related to assisting with the inflammatory process of healing. ${ }^{2,4,55,60,61}$

In regards to assisting with the healing process following fractures, a study found that fractures treated with active low intensity pulsed ultrasound (LIPUS) achieved the same level of radiographic healing and had more callus formation than inactive LIPUS 
treated fractures, as well as better fracture site mechanical properties. ${ }^{62}$ In this study, active LIPUS referred to ultrasound that provided some physiological changes, while inactive LIPUS is referred to as the placebo treatment. ${ }^{62}$ Another recent study investigated the effects of therapeutic ultrasound on femur fractures in rats. ${ }^{58}$ The authors of this study found that there was a significant increase in woven bone tissue in the fracture site of the ultrasound group, in comparison to the control group. ${ }^{58}$ This tissue regeneration was also found in a study conducted in five athletes suffering from anterior mid-tibia stress fractures. ${ }^{59}$

The inflammatory phase of the healing process is vital to proper recovery from injury and therapeutic ultrasound has been found to assist in that process. Ultrasound interacts with one or more components of inflammation and assists in earlier resolution of inflammation; it also accelerates fibrinolysis, stimulation of macrophage-derived fibroblast mitogenic factors, heightened fibroblast recruitment, accelerated angiogenesis, increased matrix synthesis, denser collagen fibrils and increased tissue tensile strength. ${ }^{53}$ LIPUS directly stimulates osteogenic cells, leading to mineralized nodule formation to regenerate osteoblasts, assisting with osteogenic differentiation. ${ }^{57}$ Improving tissue blood flow is an essential component of recovery and four studies have determined that, depending on the dosage and duration of treatment (high intensity and long duration), total forearm blood flow increased by $25 \%$ or more ${ }^{63}$ Soft tissue injuries have shown to have significant benefits of therapeutic ultrasound treatment.

Along with the benefits in the inflammatory phase of the healing process, significant changes during the proliferation and the remodeling stages of soft tissue 
injuries result from therapeutic ultrasound application. Injured tendons have shown improved breaking strengths at 5, 9, 15 and 21 days post-injury, along with increased collagen synthesis five days after injury, in comparison to untreated tendons ${ }^{64}$ In a study involving trigger points of the upper trapezius muscle, the muscle was found to contract following therapeutic ultrasound application due to the increased depth and pressure of the treatment, which resulted in relaxation of the trigger points of the upper trapezius muscle. $^{65}$

Therapeutic ultrasound is commonly used for increasing blood flow to the treatment site. The blood flow changes seen in tissues due to therapeutic ultrasound occur by the tissue temperature increasing during the treatment, and tissue heating properties of the treatment, but there is still some controversy on this potential effect. The extent of tissue heating is dependent on a number of variables. ${ }^{4}$ Specific temperature increases are required to achieve beneficial effects in the treated tissue. ${ }^{66}$ One study found that, where baseline muscle temperature was $36-37^{\circ} \mathrm{C}$, an increase of $1^{\circ} \mathrm{C}$ is considered mild heating, which accelerates metabolic rate in tissue ${ }^{66}$ For moderate heating, an increase of $2-3^{\circ} \mathrm{C}$ reduces muscle spasm, pain, chronic inflammation and increases blood flow. ${ }^{66}$ Vigorous heating increases the viscoelastic properties of collagen and inhibits sympathetic activity ${ }^{66}$ It has been suggested that tissue temperature in an area equal to the radiating area of the ultrasound applicator will increase at a rate of $0.86^{\circ} \mathrm{C}$ per minute when delivered with a stationary applicator at a frequency of $1 \mathrm{MHz}$ and at an intensity of 1.0 $\mathrm{W} / \mathrm{cm}^{2}{ }^{66}$ However, if the area is increased to twice the effective radiating area of the transducer, which is roughly less than twice the transducer surface area, the thermal effect would occur at $0.43^{\circ} \mathrm{C}$ per minute. ${ }^{66}$ In a study conducted by Draper et al. ${ }^{66}$, the 
authors found that at $3 \mathrm{MHz}$ frequency at doses of $1.5 \mathrm{~W} / \mathrm{cm}^{2}$ and $2.0 \mathrm{~W} / \mathrm{cm}^{2}$ the rate of temperature increase was so rapid that some subjects could not complete the 10 -minute treatment due to discomfort. ${ }^{66}$ The rate of heating at $1.0 \mathrm{~W} / \mathrm{cm}^{2}$ at the $1 \mathrm{MHz}$ frequency was $0.16^{\circ} \mathrm{C}$ per minute and the $3 \mathrm{MHz}$ frequency heated about three times greater than 1 MHz at all doses. ${ }^{66}$ There were no significant differences found between the maximum temperature increases for the two depths of each dose at the end of the $1 \mathrm{MHz}$ treatments. $^{66}$

There has also been research conducted to compare continuous and pulsed ultrasound treatments in regards to blood flow velocity. ${ }^{4,67}$ Intensity is one of the main factors that determine heating effect. ${ }^{4}$ Both continuous and pulsed ultrasound treatments increased intramuscular tissue temperature in all subjects. ${ }^{67}$ However, in a study conducted by Gallo et al. ${ }^{67}$, there were no statistically significant differences in the baseline temperature, the extent, or the rate of intramuscular tissue temperature increases between the pulsed and continuous ultrasound conditions. Both treatments heated the tissue at an average rate of $0.28^{\circ} \mathrm{C} / \mathrm{min} .{ }^{67}$ One study found that reduced heating occurs for pulsed ultrasound as opposed to continuous ultrasound. ${ }^{4}$ Previous research found that limiting the area treated and a treatment time of at least 7 to 8 minutes is necessary in order to achieve a rise in temperature. ${ }^{4}$

There have also been studies investigating the velocity increases in blood flow due to therapeutic ultrasound. One study using center line red blood cell velocity measurements showed decreased blood flow in 30 micrometer-diameter arterioles of rat cremaster muscle following ultrasound treatments at $1.0 \mathrm{MHz}$ and $5.0-10.0 \mathrm{~W} / \mathrm{cm}^{2}$ for 5 
minutes and an increased blood flow in larger vessels of 30-50 micrometer-diameter arterioles treated at $2.5 \mathrm{~W} / \mathrm{cm}^{2}$ for 5 minutes. ${ }^{5}$ Repeated exposure during this study over a 1- to 3-week period did not increase blood flow velocity above baseline readings; however, there was less decrease in resting blood flow velocity than the untreated control ischemic tissue. ${ }^{5}$ In another study, dogs treated with $1.0 \mathrm{~W} / \mathrm{cm}^{2}$ for 15 minutes showed a significant increase in blood flow during the last 5 minutes of treatment, but the investigators suggested that the observed increase in blood flow may have been related to the amount of hyperthermia in the treated tissue. ${ }^{5}$ In the same study, the effects of ultrasound on blood flow in humans was examined as well, and half of the subjects treated with $2.0 \mathrm{~W} / \mathrm{cm}^{2}$ for 20 minutes showed a $25 \%$ increase in blood flow when compared to the control group. ${ }^{5}$ The results of this study indicate that treatments of 1 $\mathrm{MHz}$ at 1.5 and $1.0 \mathrm{~W} / \mathrm{cm}^{2}$ showed statistically significant increases in blood flow velocity when compared with all other treatments. ${ }^{5}$ However the groups that received 3 $\mathrm{MHz}$ at 1.2 and $1.0 \mathrm{~W} / \mathrm{cm}^{2}$ showed no statistically significant changes in blood flow velocity when compared to the sham treatment. ${ }^{5}$ The study conducted by Fabrizio et al. ${ }^{5}$ suggested that these results may be due to the possibility that the massage of muscle tissue can influence autonomic functions by causing increased skin and body temperatures and alterations in respiratory rate, systolic and diastolic blood pressure, and heart rate. Therefore, based on the findings, the decreased blood flow velocity found in the sham group, which received a therapeutic ultrasound treatment with no intensity, in comparison to the control group may be due in part to the massaging effect of the ultrasound applicator head. ${ }^{5}$ The other possible factor to consider for effects of blood flow is a nonthermal mechanism of diffusion of ions. ${ }^{5}$ Studies have found that the 
microstreaming effect of ultrasound could alter cell membranes and influence the diffusion of substances and ions across the membrane. ${ }^{5}$ Another potential factor involved in hemodynamic changes may be due to the release of histamine in the treated tissue. ${ }^{5}$ It has been found that ultrasound treatment may cause degranulation of mast cells and the consequent release of histamine. ${ }^{5}$

The speed of the transducer movement may be a factor that affects the heating benefit, and in turn, the blood flow velocity of the ultrasound treatments. In previous research, it has been determined that moving the transducer head at greater than $4 \mathrm{~cm} / \mathrm{s}$ results in decreasing the total amount of energy absorbed per unit area and leads to decreased heating benefit. ${ }^{68}$ The results of the study conducted by Weaver et al. ${ }^{68}$ showed that the heating effect was similar among the different treatments regardless of the transducer velocity, such that the increases in tissue temperature reported for transducer rates of 2 to 3 and 3 to $4 \mathrm{~cm} / \mathrm{s}$ were similar to previously reported outcomes. However, the authors stated that potential differences in transducer energy output can affect temperature changes with different ultrasound transducers, even with the same treatment parameters. ${ }^{68}$ Also in regards to the transducer and the effect on heating, Demchak et al. ${ }^{69}$ compared three separate transducers that were manufactured by the same company (Accelerated CarePlus, Reno NV) and had similar ERA, power, BNR and set at the same intensity of $1.2 \mathrm{~W} / \mathrm{cm}^{2}$. The results showed that the three different transducer sizes produced different heating curves in human tissue. ${ }^{69}$

There is still controversy regarding whether blood flow increases with therapeutic ultrasound treatments. Research indicates that homeostatic mechanisms counteract the 
rise in temperature of tissues exposed to heating. ${ }^{4}$ The success of homeostasis in maintaining normal temperature depends on the balance between heat gain and heat loss. ${ }^{4}$ A study found that homeostatic control was unable to prevent the rise in tissue temperature and the authors suggest that local and general homeostatic mechanisms are only partially successful in quickly reversing the effect of a rise in tissue temperature. ${ }^{4}$ The resultant tissue temperature following heating will primarily depend on the extent of conduction into surrounding tissues and dissipation by blood perfusion. This is highly variable and difficult to determine, and known to be poor in fatty tissue and tendon. ${ }^{4}$

One study found that changes in blood flow due to heating at clinically acceptable doses are more confined to the skin, rather than deeper tissues. ${ }^{4}$ The investigators found that when using duplex ultrasound scans to measure saphenous vein cross-sectional area, heat stress resulted in doubling of the cross-sectional area and blood volume in this vein. ${ }^{4}$ An increase in blood flow gave a rapid turnover of warm blood, which assisted cooling. ${ }^{4}$ Use of radioactive tracers in human subject muscles showed that heating agents, like ultrasound, do not cause an increase in blood flow that is comparable to that caused by moderate exercise. ${ }^{4}$ There also have been many studies that did not find improvement in muscle blood flow following therapeutic ultrasound, using tolerable intensities, but it has been suggested that there may be improvements with using intolerable ultrasound intensities. $^{4}$

Another theory that is part of the controversy on this topic is increased cellular activity due to heating from therapeutic ultrasound. The type of cell affected by an increase in temperature is not specified, but the increased cellular or enzymatic activity 
implicates that this process accelerates the healing process. ${ }^{4}$ However, there is no evidence that connects these two processes. ${ }^{4}$

Increasing collagen extensibility is thought to be a result of heating with therapeutic ultrasound, but there has only been one in vivo study determining if this occurs. ${ }^{4}$ This was performed on human knees at $1.5 \mathrm{~W} / \mathrm{cm}^{2}, 1 \mathrm{MHz}$ for 8 minutes and the results indicated slight, but not significant, increases in extensibility of the lateral and medial collateral ligaments. ${ }^{4}$ There have been in vitro studies ${ }^{70-77}$ on this effect as well, but the increased extensibility with heating was very small. ${ }^{4}$

\section{Contraindications of Therapeutic Ultrasound}

While therapeutic ultrasound is a useful treatment option, there are many contraindications to be considered before application. The most cited contraindications in the research are application over the eyes, over growing epiphyseal plates or in individuals with impaired circulation. ${ }^{78}$ Another potential contraindication may be the application in individuals with DOMS ${ }^{53}$, and even though there have been benefits discovered in fracture repair, some studies have found that therapeutic ultrasound application is contraindicated in the treatment of fractures. ${ }^{62}$ These studies have found that ultrasound energy can produce significant tissue damage when applied to the skeleton because of unique biophysical interactions between ultrasound and bone. ${ }^{62}$ Ultrasound is thought to cause premature closure, slipping and displacement of the epiphyseal growth plates, bone sclerosis, diaphyseal fractures and fibrosis, and delayed healing during fracture repair. ${ }^{62}$ 
Patients may also feel the transducer head of the therapeutic ultrasound become hotter depending on the coupling agent and the amount of coupling agent used. ${ }^{1}$ The researchers found that the thicker the coupling agent, the higher the transducer temperature and the lower the transmission of the ultrasound beam. ${ }^{1}$

There are many other contraindications associated with therapeutic ultrasound, especially in regards to regions of the body where application should be avoided.

Treatment over the reproductive organs, heart, below the ribs, malignant tissue and active infection are contraindicated. ${ }^{2}$ Application over metal implants may also be contraindicated in some individuals, especially for those with total joint replacements. ${ }^{2}$

Some specific conditions are contraindications to the use of therapeutic ultrasound. If an individual has an area of decreased sensation, therapeutic ultrasound is contraindicated due to the patient's possible difficulty perceiving pain and temperature. ${ }^{2}$ Treatment of areas with decreased circulation is contraindicated as well, because excessive heat buildup can damage tissues. ${ }^{2}$ Patients with thrombophlebitis should not receive this treatment because a clot could be dislodged and create an embolus. ${ }^{2}$

\section{The Healing Process}

\section{Inflammatory Response Phase}

The healing process begins immediately after injury resulting in damage to tissues. There are three phases of the healing process: inflammatory response, fibroblastic repair and maturation remodeling. Blood flow varies considerably during this process and these changes are vital in proper recovery from injury. 
The inflammatory response phase begins immediately following injury. This phase is characterized by redness, swelling, tenderness and increased tissue temperature. ${ }^{43}$ The immediate response to tissue damage in regards to blood flow is a vasoconstriction of vascular walls in the vessels leading away from the site of injury and lasts for about five to ten minutes. ${ }^{43}$ This vasoconstriction presses the opposing endothelial wall linings together to produce a local anemia that is replaced by hyperemia of the area due to vasodilation. ${ }^{43}$ The increase in blood flow gives way to slowing of the flow in the dilated vessels, allowing circulating leukocytes to adhere to the vascular endothelium. ${ }^{43}$ This initial effusion of blood and plasma lasts for 24 to 36 hours, after which, chemical mediators flood the damaged tissue to continue the inflammatory response phase. ${ }^{43}$

Chemical mediators are derived from the presence of bacteria, damaged tissue, plasma enzyme systems and white blood cells. ${ }^{43}$ There are several chemical mediators including histamine, leukotrienes, prostaglandins and cytokines. Histamine is released from the injured mast cells and causes vasodilation and increased cell permeability, in turn, causing swelling of endothelial cells and then separation of the cells. ${ }^{43}$ Leukotrienes and prostaglandins are responsible for margination (when leukocytes, neutrophils and macrophages adhere to the cell walls), increased cell permeability and they affect the passage of fluid and white blood cells through capillary walls. ${ }^{43}$ This is accomplished through diapedesis, which leads to the formation of exudate. ${ }^{43}$ Cytokines are major regulators in leukocyte traffic and help attract leukocytes to the site of inflammation. ${ }^{43}$ The primary cytokines involved are chemokines and interleukin. ${ }^{43}$ Cytokines also cause 
phagocytes to enter the inflammation site within a few hours of injury and lead to the amount of swelling. ${ }^{43}$

The presence of the chemical mediators leads to exposure of collagen fibers in the damaged tissue. ${ }^{43}$ The exposure of the collagen fibers allows the platelets to adhere in order to create a matrix on the vascular wall where additional platelets and leukocytes adhere and form a wound plug. ${ }^{43}$ The plug acts to block the local lymphatic fluid and localize the injury response. ${ }^{43}$ Following the plug formation fibrinogen is converted to fibrin, which is the initial event that precipitates clot formation. ${ }^{43}$ Thromboplastin causes prothrombin to be changed into thrombin, which causes the conversion of fibrinogen into a fibrin clot that blocks blood supply to the injured area. ${ }^{43}$ This process begins around twelve hours after injury and finishes within 48 hours. $^{43}$ The injured area becomes walled off during this phase, to prevent the inflammation from moving to other tissues. Towards the end of this phase, granulocytes phagocytize the necrotic tissue. ${ }^{43}$ Once this process is complete, the tissue is prepared for the fibroblastic repair phase.

\section{Fibroblastic Repair Phase}

The fibroblastic repair phase is mostly characterized by fibroplasia, beginning within the first few hours after injury and lasts as long as four to six weeks. ${ }^{43}$ Many of the signs and symptoms of injury decrease during this phase, although there may still be some tenderness to touch and pain with certain movements; however, as scar formation progresses, pain and tenderness will decrease even more. ${ }^{43}$ During this process, the growth of endothelial capillary buds into the wound is stimulated by a lack of oxygen to the damaged tissue. ${ }^{43}$ Increase in blood flow is seen in this phase, which delivers 
nutrients essential for tissue regeneration in the area. ${ }^{43}$ Following this increase in blood flow, the fibrin clot is broken down, forming granulation tissue. ${ }^{43}$

The granulation tissue consists of fibroblasts, collagen and capillaries. As the capillaries continue to grow, fibroblasts accumulate at the wound site in a loose, disorganized matrix. ${ }^{43}$ Fibroblastic cells begin to synthesize an extracellular matrix that contains fibers of collagen and elastin and a ground substance that consists of nonfibrous protein called proteoglycans, glycosaminoglycans and fluid. ${ }^{43}$ By day six or seven, the fibroblasts produce collagen fibers that are deposited in a random order throughout the injured tissue forming a scar; the tensile strength of the scar increases in proportion to the rate of the collagen synthesis. ${ }^{43}$ As the strength of the scar increases, the number of fibroblasts decreases. ${ }^{43}$ At this point, the maturation remodeling phase begins.

\section{Maturation Remodeling Phase}

The maturation remodeling phase is characterized by realignment of the collagen fibers that make up the scar tissue, in proportion to the tensile forces to which that scar is subjected. ${ }^{43}$ Breakdown and synthesis of collagen are ongoing with a steady increase in the tensile strength of the scar matrix. ${ }^{43}$ Increased mechanical stress and strain on the scar leads to realignment of collagen fibers in a position of maximum efficiency parallel to the line of tension. This causes the tissue to gradually assume normal appearance and function. ${ }^{43}$ If proper stress and strain is placed on the scar matrix, at the end of this process a contracted, strong, avascular scar exists. ${ }^{43}$ This phase, however, may require several years to fully complete. 


\section{CHAPTER III}

\section{METHODS}

\section{Design}

The design of the investigation was a crossover study. The independent variables were condition (electrical stimulation and therapeutic ultrasound) and time (baseline, immediately post-treatment, 5 minutes post-treatment and 10 minutes post-treatment). The dependent variables were blood flow volume, time average mean velocity and duration of blood flow changes.

\section{Participants}

Thirty-six participants (22 females, 14 males; $21.19 \pm 1.65$ years old; $70.69 \pm$ $11.54 \mathrm{~kg} ; 170.96 \pm 9.24 \mathrm{~cm})$ volunteered to participate. The non-dominant forearm (the arm the participants choose to not write with) of all participants was chosen as the treatment site because of minimal subcutaneous fat and accessibility. ${ }^{3}$ The inclusion criteria for study was participants in good overall health between 18 and 30 years of age. The participants were excluded if they had any injury to the neck, shoulder, elbow, wrist or hand within the last year including infection, localized swelling, ${ }^{3,54}$ neuropathy or ischemia, had any known nerve conditions, bleeding conditions, had an open wound on the non-dominant arm, pregnancy, hypersensitive skin, pacemaker, heart disease, cancer, metal implants, decreased sensation, decreased circulation, thrombophlebitis, any heat sensitivities or dislike of muscle twitching sensation. ${ }^{2}$ 


\section{Instrumentation}

Therapeutic ultrasound was delivered by a Winner CM4 ultrasound machine (Rich-Mar, Chattanooga, TN). The transducer had an effective radiating area (ERA) of $4.0 \mathrm{~cm}^{2}$ and a beam non-uniformity ratio (BNR) of $<4.0$ and was calibrated before research began. ${ }^{54}$ Five milliliters of an aqueous Aquasonic Clear ultrasound gel (Parker Laboratories, Inc, Fairfield, NJ) was used as the coupling medium and kept at room temperature. $^{68}$

Electrical stimulation was delivered by a 2-channel stimulator (ARISTA 2000, Eagle Medical, St. Louis, MO). The TENS unit was set to deliver motor-level 2-Hz. Research has shown that motor-level 2-Hz application increases muscular blood flow when applied to the upper trapezius muscle. ${ }^{6}$ The frequency and intensity of the TENS was used to elicit contractions of the flexor-pronator mass of the forearm. ${ }^{6}$

Doppler ultrasound using a 5-12 MHz linear transducer (Terason T3000, Teratech, Burlington, MA) was used to monitor blood flow in the radial artery of the participants. To ensure the precision of the Doppler ultrasound operator, a reliability analysis was performed and the calculated Cronbach alpha coefficient was .38 .

All blood flow measurements were taken at the radial artery. The Doppler ultrasound also calculated time average mean velocity $(\mathrm{cm} / \mathrm{s})$ and flow volume $(\mathrm{mL} / \mathrm{min})$. 


\section{Procedures}

The participants were instructed to refrain from physical activity 24 hours before the treatment. When participants arrived for treatment, anthropometric measurements were taken (age, height and mass). Each participant was informed of the treatment procedures before signing an Institutional Review Board-approved consent form. The participant was randomly assigned to either therapeutic ultrasound or electrical stimulation for the first treatment session. Seven days later, each participant received the other treatment, following the same instructions provided during the first treatment session. The participants were instructed to wear a short-sleeved shirt in order to apply the therapeutic treatments and obtain blood flow measurements.

The participants were instructed to sit quietly for 10 minutes to allow blood flow to stabilize. ${ }^{6,19}$ Prior to the therapeutic ultrasound or electrical stimulation treatment, baseline blood flow measurements using three images were taken following the rest period, using the Doppler diagnostic ultrasound machine. (Figure 1) The primary investigator was blinded to the measurements taken specific to the treatment applied. 


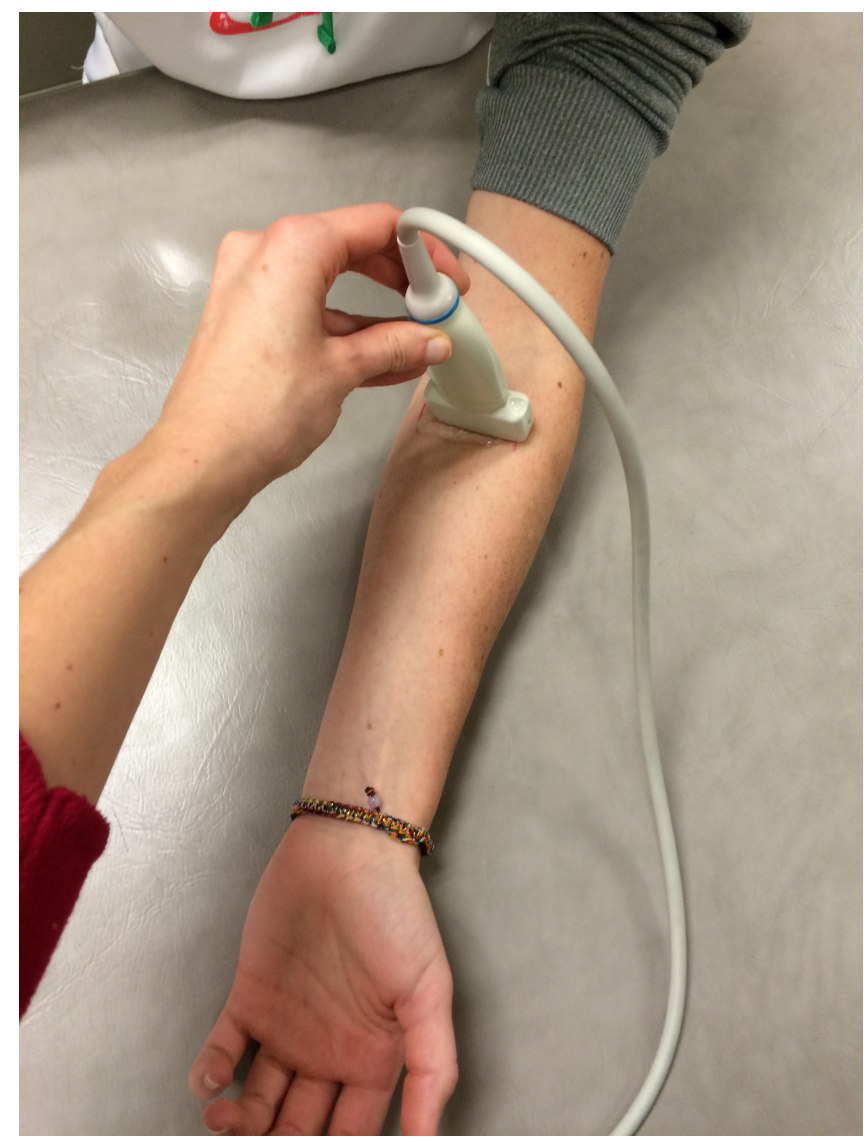

Figure 1. Diagnostic ultrasound

For the therapeutic ultrasound treatment, the participants were instructed to sit comfortably on a treatment table, with the non-dominant forearm in a supinated position. (Figure 2) The belly of the flexor-pronator mass was the site for the treatment. The therapeutic ultrasound treatment was $1 \mathrm{MHz}$, continuous, with an intensity of $1.5 \mathrm{~W} / \mathrm{cm}^{2}$ for 10 minutes. ${ }^{68}$ The treatment area was equal to twice the diameter of the transducer head. ${ }^{68}$ This was controlled for by the use of a circular-shaped template cut to twice the size of the transducer head placed on the skin. ${ }^{68}$ The transducer head was moved at a speed of $3 \mathrm{~cm} / \mathrm{s}$. The ultrasound gel was maintained at room temperature ${ }^{68}$ and applied to the skin as the coupling medium. The therapeutic ultrasound treatment was 10 minutes, 
with post-treatment blood flow measurements immediately, 5 and 10 minutes following the end of the treatment.

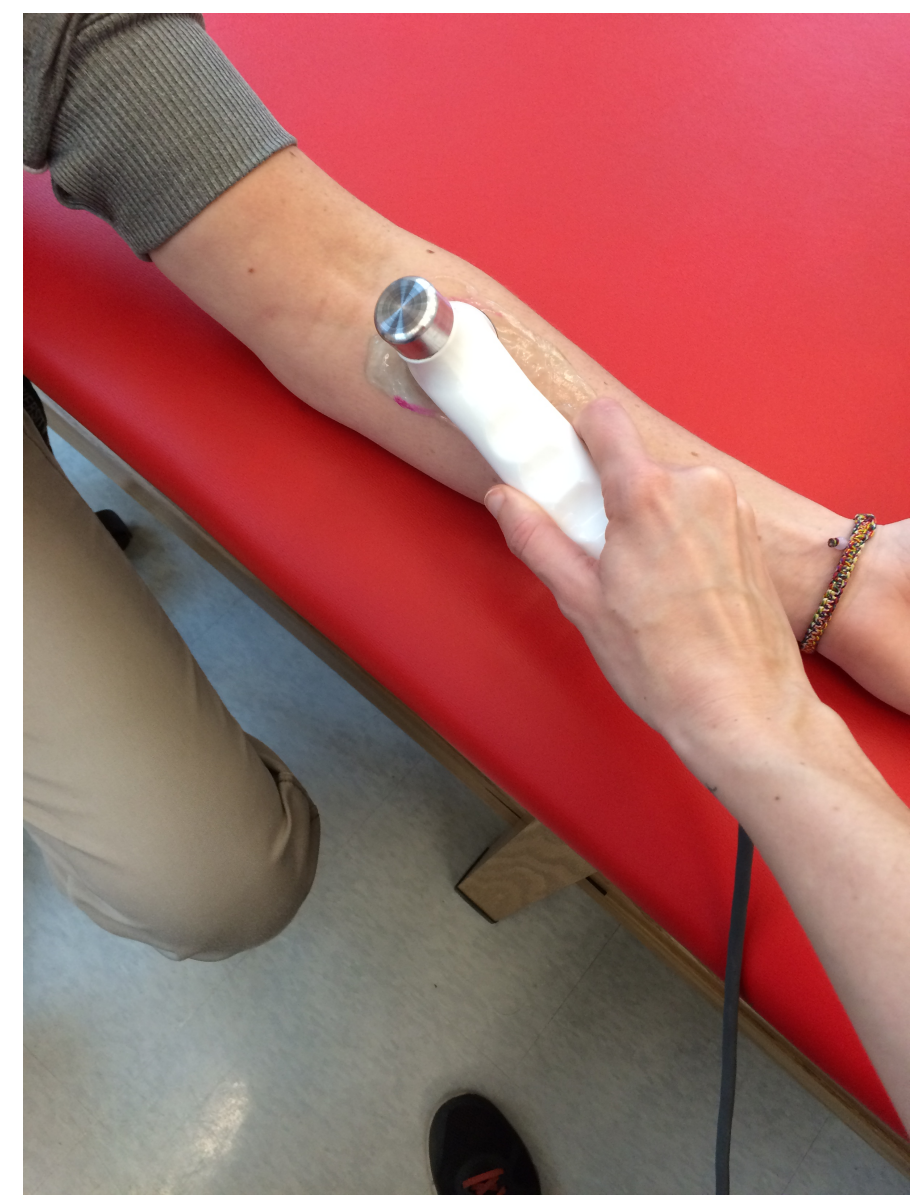

Figure 2. Therapeutic ultrasound

For the electrical stimulation treatment, the participants were instructed to sit comfortably, with the non-dominant forearm in a supinated position. (Figure 3) The electrodes were placed on the motor points of the flexor-pronator mass. The motor points were determined by visible contractions of these muscles. ${ }^{6}$ The TENS unit delivered constant asymmetrical biphasic balanced square wave pulses of low frequency $(2-\mathrm{Hz}$ burst mode, 8 pulses per burst) with a pulse duration of 180 microseconds. ${ }^{6}$ Electrical 
stimulation treatment was 15 minutes, followed by post-measurements immediately, 5 and 10 minutes after the treatment ended.

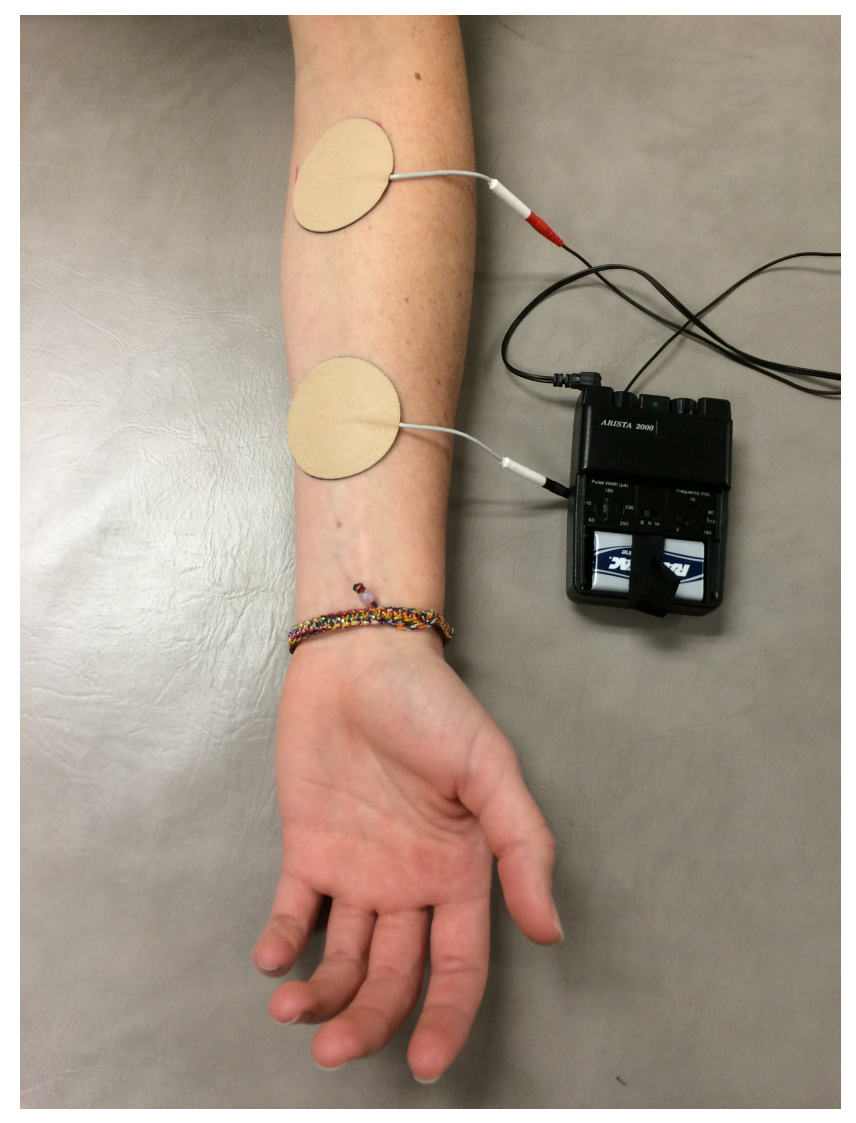

Figure 3. Electrical stimulation

\section{Statistical Analysis}

Blood flow measurements were completed with the Doppler instrument by applying vertical calipers at the start and end of the waveform, seen on the diagnostic ultrasound machine. ${ }^{19}$ The Doppler unit's built-in software calculates the time average mean velocity $(\mathrm{cm} / \mathrm{s})$ and flow volume $(\mathrm{mL} / \mathrm{min}) .{ }^{19}$ Flow volume was calculated as a product of the time average mean velocity $(\mathrm{cm} / \mathrm{s})$ and the measure of the cross-sectional area of the radial artery $\left(\mathrm{mm}^{2}\right) .{ }^{19}$ 
The radial artery blood flow data was imported and analyzed in IBM SPSS 20 statistical analysis software (IBM, Armonk, NY). A group by time analysis with two groups to compare four time segments (baseline, immediate, 5 minutes post-treatment and 10 minutes post-treatment) was used to identify differences between therapeutic ultrasound and electrical stimulation in terms of time average mean velocity and flow volume using paired t-tests $(\mathrm{P}<0.05) .{ }^{19}$ 


\section{CHAPTER IV}

\section{RESULTS}

Thirty-six participants completed all aspects of this study (22 female, 14 male; ages $21.19 \pm 1.65$ years). There were no statistically significant differences found between therapeutic ultrasound and electrical stimulation in regards to flow volume (Table 1) immediately following treatment $(4.24 \pm 1.81 \mathrm{~cm} / \mathrm{s}$ versus $3.81 \pm 1.61 \mathrm{~mL} / \mathrm{min}$, $\mathrm{P}=0.29), 5$ minutes post-treatment $(3.72 \pm 1.72 \mathrm{~mL} / \mathrm{min}$ versus $3.58 \pm 1.68 \mathrm{~mL} / \mathrm{min}, \mathrm{P}=$ $0.69)$ and 10 minutes post-treatment $(3.91 \pm 1.77 \mathrm{~mL} / \mathrm{min}$ versus $3.97 \pm 1.87 \mathrm{~mL} / \mathrm{min}, \mathrm{P}$ $=0.85)$. Further, the results were not statistically significant for differences between therapeutic ultrasound and electrical stimulation in regards to time average mean velocity (Table 2) immediately following treatment $(5.26 \pm 2.25 \mathrm{~cm} / \mathrm{s}$ versus $4.72 \pm 2.00 \mathrm{~cm} / \mathrm{s}, \mathrm{P}=$ $0.29), 5$ minutes post-treatment $(4.64 \pm 2.16 \mathrm{~cm} / \mathrm{s}$ versus $4.44 \pm 2.09 \mathrm{~cm} / \mathrm{s}, \mathrm{P}=0.65)$ and 10 minutes post-treatment $(4.84 \pm 2.19 \mathrm{~cm} / \mathrm{s}$ versus $4.94 \pm 2.34 \mathrm{~cm} / \mathrm{s}, \mathrm{P}=0.84)$.

Table 1. Flow Volume for Therapeutic Ultrasound and Electrical Stimulation. Radial artery measurements immediately post-treatment, 5 minutes post-treatment and 10 minutes post-treatment for therapeutic ultrasound and electrical stimulation.

\begin{tabular}{|c|c|c|}
\hline $\begin{array}{c}\text { Flow Volume } \\
(\mathrm{mL} / \mathrm{min}, \mathrm{SD})\end{array}$ & $\begin{array}{c}\text { Therapeutic } \\
\text { Ultrasound }\end{array}$ & Electrical Stimulation \\
\hline Baseline & $3.96 \pm 1.93$ & $4.51 \pm 1.79$ \\
\hline $\begin{array}{c}\text { Immediately Post- } \\
\text { Treatment }\end{array}$ & $4.24 \pm 1.81$ & $3.81 \pm 1.61$ \\
\hline $\begin{array}{c}5 \text { minutes Post- } \\
\text { Treatment }\end{array}$ & $3.72 \pm 1.72$ & $3.58 \pm 1.68$ \\
\hline
\end{tabular}




\begin{tabular}{|c|c|c|}
\hline $\begin{array}{c}10 \text { minutes Post- } \\
\text { Treatment }\end{array}$ & $3.91 \pm 1.77$ & $3.97 \pm 1.87$ \\
\hline
\end{tabular}

Table 2. Time Average Mean Velocity for Therapeutic Ultrasound and Electrical Stimulation. Radial artery measurements immediately post-treatment, 5 minutes posttreatment and 10 minutes post-treatment for therapeutic ultrasound and electrical stimulation.

\begin{tabular}{|c|c|c|}
\hline $\begin{array}{c}\text { Time Average Mean } \\
\text { Velocity }(\mathrm{cm} / \mathrm{s}, \mathrm{SD})\end{array}$ & $\begin{array}{c}\text { Therapeutic } \\
\text { Ultrasound }\end{array}$ & Electrical Stimulation \\
\hline Baseline & $4.92 \pm 2.39$ & $5.62 \pm 2.23$ \\
\hline $\begin{array}{c}\text { Immediately Post- } \\
\text { Treatment }\end{array}$ & $5.26 \pm 2.25$ & $4.72 \pm 2.00$ \\
\hline $\begin{array}{c}5 \text { minutes Post- } \\
\text { Treatment }\end{array}$ & $4.64 \pm 2.16$ & $4.44 \pm 2.09$ \\
\hline $\begin{array}{c}10 \text { minutes Post- } \\
\text { Treatment }\end{array}$ & $4.85 \pm 2.19$ & $4.94 \pm 2.34$ \\
\hline
\end{tabular}

For comparison within the treatments, there were no statistically significant differences in flow volume or time average mean velocity for any of the measurement times for therapeutic ultrasound. The results for therapeutic ultrasound flow volume and time average mean velocity are included in Table 3.

Table 3. Flow Volume and Time Average Mean Velocity for Therapeutic Ultrasound. Immediately post-treatment, 5 minutes post-treatment and 10 minutes post-treatment compared to baseline measurements for therapeutic ultrasound.

\begin{tabular}{|c|c|c|}
\hline $\begin{array}{c}\text { Therapeutic } \\
\text { Ultrasound }\end{array}$ & $\begin{array}{c}\text { Flow Volume } \\
(\mathrm{mL} / \mathrm{min})\end{array}$ & $\begin{array}{c}\text { Time Average Mean } \\
\text { Velocity }(\mathrm{cm} / \mathrm{s})\end{array}$ \\
\hline $\begin{array}{c}\text { Baseline vs. } \\
\text { Immediately Post- } \\
\text { Treatment }\end{array}$ & $\begin{array}{c}3.96 \pm 1.93 \text { vs. } 4.24 \pm \\
4.92 \pm 2.39 \text { vs. } 5.26 \pm \\
2.25\end{array}$ \\
\hline $\begin{array}{c}\text { Baseline vs. 5 minutes } \\
\text { Post-Treatment }\end{array}$ & $3.96 \pm 1.93$ vs. $3.72 \pm$ & $4.92 \pm 2.39$ vs. $4.64 \pm$ \\
\hline $\begin{array}{c}\text { Baseline vs. } 10 \\
\text { minutes Post- } \\
\text { Treatment }\end{array}$ & $3.96 \pm 1.93$ vs. $3.91 \pm$ & $4.92 \pm 2.39$ vs. $4.85 \pm$ \\
& 1.77 & 2.19 \\
\hline
\end{tabular}


While there were no significant differences found within the time frames of measurements for therapeutic ultrasound, there were statistically significant differences found when comparing electrical stimulation baseline blood flow measurements and immediately post-treatment and 5 minutes post-treatment, but not at 10 minutes posttreatment. The results for measurement of flow volume and time average mean velocity following the electrical stimulation treatments are included in Table 4. The effect size correlation for flow volume baseline vs. immediately post-treatment (.20) and baseline vs. 5 minutes post-treatment (.25) indicates a small effect size. ${ }^{79}$ The effect size correlation for time average mean velocity baseline vs. immediately post-treatment (.20) indicates a small effect size and the effect size correlation for baseline vs. 5 minutes posttreatment (.54) indicates a medium effect size. ${ }^{79}$

Table 4. Flow Volume and Time Average Mean Velocity for Electrical Stimulation. Immediately post-treatment, 5 minutes post-treatment and 10 minutes post-treatment compared to baseline measurements for electrical stimulation.

\begin{tabular}{|c|c|c|}
\hline Electrical Stimulation & $\begin{array}{l}\text { Flow Volume } \\
\text { ( } \mathrm{mL} / \mathrm{min})\end{array}$ & $\begin{array}{l}\text { Time Average Mean } \\
\text { Velocity }(\mathrm{cm} / \mathrm{s})\end{array}$ \\
\hline $\begin{array}{l}\text { Baseline vs. } \\
\text { Immediately Post- } \\
\text { Treatment }\end{array}$ & $\begin{array}{c}4.51 \pm 1.79 \text { vs. } 3.81 \pm \\
1.61^{*}\end{array}$ & $\begin{array}{c}5.62 \pm 2.23 \text { vs. } 4.72 \pm \\
2.00^{*}\end{array}$ \\
\hline $\begin{array}{l}\text { Baseline vs. } 5 \text { minutes } \\
\text { Post-Treatment }\end{array}$ & $\begin{array}{c}4.51 \pm 1.79 \text { vs. } 3.58 \pm \\
1.68^{*}\end{array}$ & $\begin{array}{c}5.62 \pm 2.23 \text { vs. } 4.44 \pm \\
2.09 *\end{array}$ \\
\hline $\begin{array}{c}\text { Baseline vs. } 10 \\
\text { minutes Post- } \\
\text { Treatment }\end{array}$ & $\begin{array}{c}4.51 \pm 1.79 \text { vs. } 3.97 \pm \\
1.87\end{array}$ & $\begin{array}{c}5.62 \pm 2.23 \text { vs. } 4.94 \pm \\
2.34\end{array}$ \\
\hline
\end{tabular}

* Indicates group-by-time interaction $(\mathrm{P}<0.05)$ 


\section{CHAPTER V \\ DISCUSSION}

We expected to find that a significant difference would occur when comparing therapeutic ultrasound to electrical stimulation as a modality to increase blood flow in the arm. Our results do not support this hypothesis. However, we did find that the application of TENS significantly decreased radial artery blood flow immediately following treatment, as well as 5 minutes post-treatment, in comparison to baseline blood flow measurements. However, blood flow changes were no longer significant at 10 minutes post-treatment following TENS.

Previous research regarding effecting blood flow in the forearm using two different treatment parameters for TENS found small changes in cutaneous blood flow and skin temperature. ${ }^{7}$ The two treatment parameters used in this study were low frequency TENS (4 Hz/200 microseconds) and high frequency TENS (110 Hz/200 microseconds), as well as a control treatment. ${ }^{7}$ This study showed that there were no significant differences between high and low frequency TENS for cutaneous blood flow or skin temperature in the forearm, although there was a small and short lived increase in cutaneous blood flow at the index finger in the TENS groups compared to the control group when TENS was turned off.' Overall, this study found that the effects of low frequency and high frequency TENS produced minimal changes in blood flow and skin 
temperature. Levine et al. ${ }^{10}$ used electrical stimulation on the gluteus maximus of healthy individuals as well as spinal cord injured individuals and found that during stimulation. rest periods blood flow decreased in healthy participants. The authors suggest that the tissue gradually distorts and doesn't reach peak occlusion for a relatively long time, therefore leading to the decrease in blood flow. ${ }^{10}$ Reeves et al. ${ }^{80}$ applied TENS to determine if there was an effect on the sympathetic nervous system, by measuring heart rate, digital pulse volume and skin conductance. This study found that there were no effects on the sympathetic nervous system, which could potentially explain the decrease found in the current study. While this study found minimal changes in blood flow, variances in treatment parameters make a significant impact on accomplishing this goal.

Treatment parameters of electrical stimulation impact the effects that occur in the applied tissues. Sandberg et al. ${ }^{6}$ applied TENS to the upper trapezius muscle in subjects using three different treatment parameters, all for 15 minutes: high frequency $(80 \mathrm{~Hz})$ and sensory level intensity; low frequency $(2 \mathrm{~Hz})$ and motor level intensity; and subsensory $80 \mathrm{~Hz}$ TENS used as a control. Muscular and skin blood flow were measured in this study and the results showed that trapezius muscle blood flow increased significantly with motor level $2 \mathrm{~Hz}$ TENS, while there was no increase found with sensory level $80 \mathrm{~Hz}$ TENS or subsensory $80 \mathrm{~Hz}$ TENS. ${ }^{6}$ In regards to skin blood flow measurements, there were no significant increases found with any of these treatments. ${ }^{6}$ Miller et al. ${ }^{29}$ applied TENS to the gastrocnemius muscle with a frequency of $2500 \mathrm{~Hz}$ and a burst frequency of $20 \mathrm{~Hz}$. The stimulation level for this study was set at a level that elicited the strongest plantar-flexor contraction that could be tolerated by the participants. ${ }^{29}$ Overall, this study showed that the increase in blood flow and decrease in vascular resistance persisted until 
the 15 -second post-exercise measurements, but the increase was minimal and short lived. ${ }^{29}$ A review conducted by Machado et al.$^{81}$ discussed that while there have been improvements in blood flow seen following TENS application with both low frequency ( $2 \mathrm{~Hz}$ to $4 \mathrm{~Hz}$ ) and high frequency $(75 \mathrm{~Hz}$ to $100 \mathrm{~Hz}$ ). However, there is a lack of consensus as to whether TENS does improve blood flow, according to this review. The results of the current study showed that electrical stimulation does affect blood flow in comparison to baseline measurements, but comparing electrical stimulation to therapeutic ultrasound found no significant differences.

Some studies have found that the only improvements in blood flow following therapeutic ultrasound are seen with intolerable intensities for the participants. In a study exploring muscle temperature, at $1 \mathrm{MHz}, 1.5 \mathrm{~W} / \mathrm{cm}^{2}$ and $2.0 \mathrm{~W} / \mathrm{cm}^{2}$, the rate of temperature increase was so rapid that some of the participants were not able to complete the 10-minute treatment due to discomfort. ${ }^{66}$ Shaik et al. ${ }^{54}$ used two treatment parameters on subjects: pulsed ultrasound at $3 \mathrm{MHz}, 1: 4$ duty cycle, at an intensity of $0.25 \mathrm{~W} / \mathrm{cm}^{2}$ for 5 minutes and continuous ultrasound at $1 \mathrm{MHz}$, at an intensity of $0.8 \mathrm{~W} / \mathrm{cm}^{2}$ for 3 minutes. The results of this study found that there was a significant decrease in skin blood flow over the treatment area, comparing baseline to post-treatment measurements following both treatments. ${ }^{54}$ Skin blood flow was measured using a spectroscopy camera, examining the red blood cell concentration in dermal tissue. ${ }^{54}$ Pulsed ultrasound at 3 $\mathrm{MHz}$ resulted in a significant decrease in superficial blood flow as compared to that of the control condition. ${ }^{54}$ In a treatment applied to the forearm of participants, continuous ultrasound was applied at $1 \mathrm{MHz}, 1.5 \mathrm{~W} / \mathrm{cm}^{2}$ for 5 minutes found that muscle, skin and forearm blood flow was not significantly different between the control and ultrasound- 
treated arms. ${ }^{63}$ There was a significant time effect found for skin and forearm blood flow in that comparisons of pretreatment and post-treatment values demonstrated that skin blood flow significantly increased through 15 minutes, and forearm blood flow was increased through 5 minutes, but no significant time effect was found for muscle blood flow. ${ }^{63}$ A review conducted by Baker et al. ${ }^{4}$ discussed that there is a possibility that ultrasound at higher intensities may increase muscular blood flow, due to previous studies. However, the intensities selected proved to be intolerable for participants, so this increase is likely not achievable clinically using therapeutic ultrasound. ${ }^{4}$

As with all research, our study did have some limitations. The sample size was relatively small, so further research with a larger sample size is needed to determine if the effects are the same in a larger sample of subjects. This study was conducted on a healthy population, even though the treatments would normally be applied to patients with an injury, so further research is necessary to determine if the same effects would appear in a population with an orthopedic injury. Another limitation in this study is that only radial artery blood flow was measured, so further research is necessary to determine if TENS would cause the same results on another artery. Reliability is another limitation of this study. The reliability for diagnostic ultrasound in this study was low (Cronbach alpha coefficient of .38), which could be caused by a few factors including researcher inexperience in utilizing diagnostic ultrasound, activity level of participants prior to data collection, or food/drink consumption by participants prior to data collection.

This study showed that therapeutic ultrasound did not improve radial artery blood flow when compared to baseline measurements or compared to electrical stimulation 
blood flow measurements. However, the results did show that electrical stimulation decreased blood flow immediately following treatment and at 5 minutes post-treatment, but not at 10 minutes post-treatment when compared to baseline measurements. From these results, there may be a 5 minute time frame following the TENS application during which blood flow is decreased in the forearm thereby providing a temporary timeframe for the control of edema or effusion. 


\section{REFERENCES}

1. Draper DO, Edvalson CG, Knight KL, Eggett D, Shurtz J. Temperature increases in the human achilles tendon during ultrasound treatments with commercial ultrasound gel and full-thickness and half-thickness gel pads. J Athl Train. 2010;45(4):333-337.

2. Knight KL, Draper DO. Therapeutic modalities: The art and science. Philadelphia, PA: Lippincott Williams \& Wilkins; 2008.

3. Chan AK, Myrer JW, Measom GJ, Draper DO. Temperature changes in human patellar tendon in response to therapeutic ultrasound. $J$ Athl Train. 1998;33(2):130-135.

4. Baker KG, Robertson VJ, Duck FA. A review of therapeutic ultrasound: Biophysical effects. Phys Ther. 2001;81(7):1351-8.

5. Fabrizio PA, Schmidt JA, Clemente FR, Lankiewicz LA, Levine ZA. Acute effects of therapeutic ultrasound delivered at varying parameters on the blood flow velocity in a muscular distribution artery. J Orthop Sports Phys Ther. 1996;24(5):294-302.

6. Sandberg ML, Sandberg MK, Dahl J. Blood flow changes in the trapezius muscle and overlying skin following transcutaneous electrical nerve stimulation. Physical Therapy. 2007;87(8):1047-1055. 
7. Chen C, Johnson M, McDonough S, Cramp F. The effect of transcutaneous electrical nerve stimulation on local and distal cutaneous blood flow following a prolonged heat stimulus in healthy subjects. Clin Physiol Funct Imaging. 2007;27(3):154-61.

8. Currier DP, Petrilli CR, Threlkeld AJ. Effect of graded electrical stimulation on blood flow to healthy muscle. Physical Therapy. 1986;66(6):937-943.

9. Broderick BJ, Breathnach O, Condon F, Masterson E, Olaighin G. Haemodynamic performance of neuromuscular electrical stimulation (NMES) during recovery from total hip arthroplasty. J Orthop Surg Res. 2013;8:3-799X-83.

10. Levine SP, Kett RL, Gross MD, Wilson BA, Cederna PS, Juni JE. Blood flow in the gluteus maximus of seated individuals during electrical muscle stimulation. Arch Phys Med Rehabil. 1990;71(9):682-686.

11. Ebadi S, Henschke N, Nakhostin Ansari N, Fallah E, van Tulder M. Therapeutic ultrasound for chronic low-back pain. Cochrane Database Syst Rev. 2014;3:CD009169.

12. Shier D, Butler J, Lewis R. Hole's human anatomy \& physiology. 12th ed. New York, NY: McGraw-Hill; 2010.

13. Cuppett M, Walsh KM. General medical conditions in the athlete. 2nd ed. St. Louis, MO: Elsevier Mosby; 2012:363-364.

14. Prentice WE. Skin disorders. In: Principles of athletic training: A competency-based approach. 14th ed. New York, NY: McGraw-Hill; 2011:857-858. 
15. Moore KL, Dalley AF, Agur AMR. Clinically oriented anatomy. 6th ed. Lippincott Williams \& Wilkins; 2010.

16. Baldwin ERL, Baldwin T, Lancaster J, McNeely M, Collins D. Neuromuscular electrical stimulation and exercise for reducing trapezius muscle dysfunction in survivors of head and neck cancer: A case-series report. Physiother Can. 2012;64(3):317-24.

17. Barker K, Elliott C, Sackley C, Fairbank JCT. Treatment of chronic back pain by sensory discrimination training. A phase I RCT of a novel device (FairMed) vs. TENS. BMC musculoskeletal disorders. 2008;9:97.

18. Bogie K, Triolo R. Effects of regular use of neuromuscular electrical stimulation on tissue health. J Rehabil Res Dev. 2003;40(6):469-75.

19. Broderick BJ, O'Connell S, Moloney S, et al. Comparative lower limb hemodynamics using neuromuscular electrical stimulation (NMES) versus intermittent pneumatic compression (IPC). Physiol Meas. 2014;35(9):1849-1859.

20. Bruce Brand R, Walls R, Ong J, Emerson B, O'Byrne J, Moyna N. Effects of homebased resistance training and neuromuscular electrical stimulation in knee osteoarthritis: A randomized controlled trial. BMC musculoskeletal disorders. 2012;13:118.

21. Carty A, McCormack K, Coughlan G, Crowe L, Caulfield B. Alterations in body composition and spasticity following subtetanic neuromuscular electrical stimulation training in spinal cord injury. $J$ Rehabil Res Dev. 2013;50(2):193-202. 
22. Chesterton L, van der Windt, Daniëlle A, Sim J, et al. Transcutaneous electrical nerve stimulation for the management of tennis elbow: A pragmatic randomized controlled trial: The TATE trial (ISRCTN 87141084). BMC Musculoskelet Disord. 2009;10:156.

23. Clarke Moloney M, Lyons GM, Breen P, Burke PE, Grace PA. Haemodynamic study examining the response of venous blood flow to electrical stimulation of the gastrocnemius muscle in patients with chronic venous disease. Eur $J$ Vasc Endovasc Surg. 2006;31(3):300-5.

24. Doucet B, Lam A, Griffin L. Neuromuscular electrical stimulation for skeletal muscle function. Yale J Biol Med. 2012;85(2):201-15.

25. Fary R, Briffa N. Monophasic electrical stimulation produces high rates of adverse skin reactions in healthy subjects. Physiother Theory Pract. 2011;27(3):246-51.

26. Giavedoni S, Deans A, McCaughey P, Drost E, MacNee W, Rabinovich R. Neuromuscular electrical stimulation prevents muscle function deterioration in exacerbated COPD: A pilot study. Respir Med. 2012;106(10):1429-34 .

27. Gulick DT, Castel JC, Palermo FX, Draper DO. Effect of patterned electrical neuromuscular stimulation on vertical jump in collegiate athletes. Sports Health. 2011;3(2):152-157.

28. Iwasa J, Ochi M, Uchio Y, Adachi N, Kawasaki K. Decrease in anterior knee laxity by electrical stimulation of normal and reconstructed anterior cruciate 
ligaments. The Journal of Bone and Joint Surgery.British Volume. 2006;88(4):477-83.

29. Miller BF, Gruben KG, Morgan BJ. Circulatory responses to voluntary and electrically induced muscle contractions in humans. Phys Ther. 2000;80(1):53-60.

30. Palmer S, Domaille M, Cramp F, et al. Transcutaneous electrical nerve stimulation as an adjunct to education and exercise for knee osteoarthritis: A randomized controlled trial. Arthritis Care Res (Hoboken). 2014;66(3):387-94.

31. Polak A, Franek A, Taradaj J. High-voltage pulsed current electrical stimulation in wound treatment. Adv Wound Care (New Rochelle). 2014;3(2):104-117.

32. Sayenko D, Nguyen R, Popovic M, Masani K. Reducing muscle fatigue during transcutaneous neuromuscular electrical stimulation by spatially and sequentially distributing electrical stimulation sources. Eur J Appl Physiol. 2014;114(4):793-804.

33. Smit CAJ, Legemate KJA, de Koning A, de Groot S, Stolwijk Swuste J, Janssen TWJ. Prolonged electrical stimulation-induced gluteal and hamstring muscle activation and sitting pressure in spinal cord injury: Effect of duty cycle. J Rehabil Res Dev. 2013;50(7):1035-46.

34. Solis L, Twist E, Seres P, Thompson R, Mushahwar V. Prevention of deep tissue injury through muscle contractions induced by intermittent electrical stimulation after spinal cord injury in pigs. $J$ Appl Physiol. 2013;114(2):286-96. 
35. Stenberg W. TENS-induced pain control in a malignant hyperthermia-susceptible patient. Anesth Prog. 1994;41(4):100-1.

36. Torkaman G. Electrical stimulation of wound healing: A review of animal experimental evidence. Advances in wound care. 2014;3(2):202-218.

37. Tsukayama H, Yamashita H, Amagai H, Tanno Y. Randomised controlled trial comparing the effectiveness of electroacupuncture and TENS for low back pain: A preliminary study for a pragmatic trial. Acupuncture in medicine. $2002 ; 20(4): 175-80$.

38. Walls R, McHugh G, O'Gorman D, Moyna N, O'Byrne J. Effects of preoperative neuromuscular electrical stimulation on quadriceps strength and functional recovery in total knee arthroplasty. A pilot study. BMC musculoskeletal disorders. 2010;11:119.

39. Deyo RA, Walsh NE, Martin DC, Schoenfeld LS, Ramamurthy S. A controlled trial of transcutaneous electrical nerve stimulation (TENS) and exercise for chronic low back pain. New Engl J Med. 1990;322(23):1627-1634.

40. Valenti F. Neuromuscular electrical stimulation in clinical practice. Acta Anaesthesiol. 1964;15:227-245.

41. Izumi M, Ikeuchi M, Mitani T, Taniguchi S, Tani T. Prevention of venous stasis in the lower limb by transcutaneous electrical nerve stimulation. European journal of vascular and endovascular surgery. 2010;39(5):642-5.

42. Monaco A, Sgolastra F, Pietropaoli D, Giannoni M, Cattaneo R. Comparison between sensory and motor transcutaneous electrical nervous stimulation on electromyographic and kinesiographic activity of patients with 
temporomandibular disorder: A controlled clinical trial. $B M C$ Musculoskelet Disord. 2013;14:168.

43. Prentice WE. Rehabilitation techniques for sports medicine and athletic training. 5th ed. New York, NY: McGraw-Hill; 2011.

44. Abramson DI, Burnett C, Bell Y, Tuck S. Changes in blood flow, oxygen uptake and tissue temperatures produced by therapeutic physical agents. Am J Phys Med. 1960;47:51-62.

45. Milnor W. Autonomic and peripheral control mechanisms. Medical Physiology. 1980;2(14):1047-1060.

46. Fountain FP, Gersten JW, Sengu 0. Decrease in muscle spasm produced by ultrasound, hot packs, and IR. Arch Phys Med Rehabil. 1960;41:293-298.

47. Kuitert J. Ultrasonic energy as an adjunct in the management of radiculitis and similar referred pain. Am J Phys Med. 1954;33:61.

48. LeBan M. Collagen tissue: Implications of its response to stress in vitro. Arch Phys Med Rehabil. 1962;43:461-466.

49. Lehmann JF, Masock AJ, Warren CG, Koblanski JN. Effect of therapeutic temperatures on tendon extensibility. Arch Phys Med Rehabil. 1970;51:481-487.

50. Lehmann JF, DeLateur BJ, Warren CG, Stonebridge JB. Heating produced by ultrasound in bone and soft tissue. Arch Phys Med Rehabil. 1967;48:397401.

51. Lehmann JF DB. Therapeutic heat. In: Therapeutic heat and cold. 3rd ed. Baltimore, MD: Williams \& Wilkins; 1982:487-562. 
52. Harvey W, Dyson M, Pond JB, Grahame R. The "in vivo" stimulation of protein synthesis in human fibroblasts by therapeutic levels of ultrasound. proceedings of the second european congress on ultrasound in medicine. Excerpta Med Int Cong Ser. 1975;363:10-21.

53. Speed CA. Therapeutic ultrasound in soft tissue lesions. Rheumatology. 2001;40(12):1331-1336.

54. Shaik SS, MacDermid JC, Birmingham T, Grewal R, Farooq B. Short-term sensory and cutaneous vascular responses to therapeutic ultrasound in the forearms of healthy volunteers. $J$ Ther Ultrasound. 2014;2:10-5736-2-10. eCollection 2014.

55. Johns L. Nonthermal effects of therapeutic ultrasound: The frequency resonance hypothesis. Journal of athletic training. 2002;37(3):293-9.

56. Gill IPS, Montgomery R, Wallis J. Successful treatment of sternal non-union by ultrasound. Interact Cardiovasc Thorac Surg. 2009;9(3):389-90.

57. Ogawa T, Ochiai N, Nishiura Y, Tanaka T, Hara Y. A new treatment strategy for kienböck's disease: Combination of bone marrow transfusion, lowintensity pulsed ultrasound therapy, and external fixation. Journal of orthopaedic science. 2013;18(2):230-7.

58. Oliveira P, Sperandio E, Fernandes K, Pastor FAC, Nonaka K, Renno ACM. Comparison of the effects of low-level laser therapy and low-intensity pulsed ultrasound on the process of bone repair in the rat tibia. Brazilian Journal of Physical Therapy. 2011;15(3):200-5. 
59. Uchiyama Y, Nakamura Y, Mochida J, Tamaki T. Effect of low-intensity pulsed ultrasound treatment for delayed and non-union stress fractures of the anterior mid-tibia in five athletes. Tokai J Exp Clin Med. 2007;32(4):1215.

60. Ying Z, Lin T, Yan S. Low-intensity pulsed ultrasound therapy: A potential strategy to stimulate tendon-bone junction healing. Journal of Zhejiang University (Science) B. 2012;13(12):955-63.

61. Hosseinkhah N, Hynynen K. A three-dimensional model of an ultrasound contrast agent gas bubble and its mechanical effects on microvessels. Phys Med Biol. 2012;57(3):785-808.

62. Warden SJ, Fuchs RK, Kessler CK, Avin KG, Cardinal RE, Stewart RL. Ultrasound produced by a conventional therapeutic ultrasound unit accelerates fracture repair. Physical Therapy. 2006;86(8):1118-1127.

63. Robinson SE, Buono MJ. Effect of continuous-wave ultrasound on blood flow in skeletal muscle. Phys Ther. 1995;75(2):145-9; discussion 149.

64. Larsen A, Kristensen G, Thorlacius-Ussing O, Oxlund H. The influence of ultrasound on the mechanical properties of healing tendons in rabbits. Acta Orthop. 2005;76(2):225-230.

65. Draper DO, Mahaffey C, Kaiser D, Eggett D, Jarmin J. Thermal ultrasound decreases tissue stiffness of trigger points in upper trapezius muscles. Physiother Theory Pract. 2010;26(3):167-172. 
66. Draper DO, Castel JC. Rate of temperature increase in human muscle during $1 \mathrm{MHz}$ and $3 \mathrm{MHz}$ continuous ultrasound. J Orthop Sports Phys Ther. 1995;22(4):142-50.

67. Gallo JA, Draper DO, Brody LT, Fellingham GW. A comparison of human muscle temperature increases during 3-MHz continuous and pulsed ultrasound with equivalent temporal average intensities. J Orthop Sports Phys Ther. 2004;34(7):395-401.

68. Weaver SL, Demchak TJ, Stone MB, Brucker JB, Burr PO. Effect of transducer velocity on intramuscular temperature during a $1-\mathrm{MHz}$ ultrasound treatment. J Orthop Sports Phys Ther. 2006;36(5):320-5.

69. Demchak TJ, Straub SJ, Johns LD. Ultrasound heating is curvilinear in nature and varies between transducers from the same manufacturer. $J$ Sport Rehabil. 2007;16(2):122-30.

70. World federation for ultrasound in medicine and biology. conclusions and recommendations on thermal and non-thermal mechanisms for biological effects of ultrasound. WFUMB News. 1997;4:2-4.

71. Fahnestock M, Rimer VG, Yamawaki PR, Edmonds PD. Effects of ultrasound exposure in vitro on neuroblastoma cell membranes. Ultrasound Med Biol. $1989 ; 15: 133-144$.

72. Harvey W, Dyson M, Pond J, et al. Metabolic changes induced by ultrasound in fibroblasts in vitro. in: Kazner E, de vlieger M, muller $<$ br $/>H R$, McCready VR, eds. proceedings of the second european congress on $<\mathrm{br}$ 
>Ultrasonics in medicine. Amsterdam, the Netherlands: Excerpta Medica. 1975:10-21.

73. Ramirez A, Schwane JA, McFarland C, Starcher B. The effect of ultrasound on collagen synthesis and fibroblast proliferation in vitro. Med Sci Sport Exerc. 1997;29:326-332.

74. Robertson VJ WA. Dangers in extrapolating in vitro uses of therapeutic ultrasound [letter]. Phys Ther. 1996;76:78-79.

75. Vander A, Sherman J, Luciano D. Human physiology: The mechanism of body function. Boston, MA: WCB McGraw-Hill; 1998.

76. Watson JD, Gilman M, Witkowki J, Zoller M. Recombinant DNA. New York, NY: Scientific American Books; 1992.

77. Williams A. Ultrasound: Biological effects and potential hazards. London, England: Academic Press. 1983.

78. Batavia M. Contraindications for superficial heat and therapeutic ultrasound: Do sources agree? Arch Phys Med Rehabil. 2004;85(6):1006-12.

79. Berg K, Latin R. Essentials of research methods in health, physical education, exercise science, and recreation. 3rd ed. Lippincott Williams \& Wilkins; 2008.

80. Reeves J, Graff Radford S, Shipman D. The effects of transcutaneous electrical nerve stimulation on experimental pain and sympathetic nervous system response. Pain Med. 2004;5(2):150-161. 
81. Machado AFP, Santana E, Tacani P, Liebano R. The effects of transcutaneous electrical nerve stimulation on tissue repair: A literature review. Can J Plast Surg. 2012;20(4):237-240. 